\title{
Unconjugated PLGA nanoparticles attenuate temperature-dependent $\beta$-amyloid aggregation and protect neurons against toxicity: implications for Alzheimer's disease pathology
}

Pallabi Sil Paul', Jae-Young Cho², Qi Wu', Govindarajan Karthivashan', Emily Grabovac², Holger Wille, Marianna Kulka ${ }^{2,4}$ and Satyabrata $\operatorname{Kar}^{1,5^{*}}$ (D)

\begin{abstract}
Conversion of $\beta$-amyloid $(A \beta)$ peptides from soluble random-coil to aggregated protein enriched with $\beta$-sheet-rich intermediates has been suggested to play a role in the degeneration of neurons and development of Alzheimer's disease (AD) pathology. Aggregation of $A \beta$ peptide can be prompted by a variety of environmental factors including temperature which can influence disease pathogenesis. Recently, we reported that FDA-approved unconjugated poly (D,L-lactide-co-glycolide) (PLGA) nanoparticles can have beneficial effects in cellular and animal models of AD by targeting different facets of the $A \beta$ axis. In this study, using biochemical, structural and spectroscopic analyses, we evaluated the effects of native PLGA on temperature-dependent $A \beta$ aggregation and its ability to protect cultured neurons from degeneration. Our results show that the rate of spontaneous $A \beta_{1-42}$ aggregation increases with a rise in temperature from 27 to $40^{\circ} \mathrm{C}$ and PLGA with 50:50 resomer potently inhibits $A \beta$ aggregation at all temperatures, but the effect is more profound at $27^{\circ} \mathrm{C}$ than at $40^{\circ} \mathrm{C}$. It appears that native PLGA, by interacting with the hydrophobic domain of $A \beta_{1-42}$, prevents a conformational shift towards $\beta$-sheet structure, thus precluding the formation of $A \beta$ aggregates. Additionally, PLGA triggers disassembly of matured $A \beta_{1-42}$ fibers at a faster rate at $40^{\circ} \mathrm{C}$ than at $27^{\circ} \mathrm{C}$. PLGA-treated A $\beta$ samples can significantly enhance viability of cortical cultured neurons compared to neurons treated with $A \beta$ alone by attenuating phosphorylation of tau protein. Injection of native PLGA is found to influence the breakdown/clearance of $A \beta$ peptide in the brain. Collectively, these results suggest that PLGA nanoparticles can inhibit $A \beta$ aggregation and trigger disassembly of $A \beta$ aggregates at temperatures outside the physiological range and can protect neurons against $A \beta$-mediated toxicity thus validating its unique therapeutic potential in the treatment of AD pathology.
\end{abstract}

Keywords: Alzheimer's disease, $\beta$-amyloid aggregation, PLGA nanoparticles, Neuroprotection

\footnotetext{
*Correspondence: skar@ualberta.ca

${ }^{5}$ Departments of Medicine (Neurology) and Psychiatry, Centre for Prions

and Protein Folding Diseases, University of Alberta, Edmonton, AB T6G

2M8, Canada

Full list of author information is available at the end of the article
}

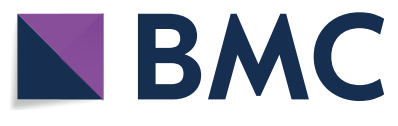

(c) The Author(s) 2022, corrected publication 2022 Open Access This article is licensed under a Creative Commons Attribution 4.0 International License, which permits use, sharing, adaptation, distribution and reproduction in any medium or format, as long as you give appropriate credit to the original author(s) and the source, provide a link to the Creative Commons licence, and indicate if changes were made. The images or other third party material in this article are included in the article's Creative Commons licence, unless indicated otherwise in a credit line to the material. If material is not included in the article's Creative Commons licence and your intended use is not permitted by statutory regulation or exceeds the permitted use, you will need to obtain permission directly from the copyright holder. To view a copy of this licence, visit http://creativecommons.org/licenses/by/4.0/. The Creative Commons Public Domain Dedication waiver (http://creativecommons.org/publicdomain/zero/1.0/) applies to the data made available in this article, unless otherwise stated in a credit line to the data. 


\section{Graphical Abstract}

Unconjugated PLGA nanoparticles attenuate temperature-dependent $\beta$-amyloid aggregation and protect neurons against toxicity: implications for Alzheimer's disease pathology

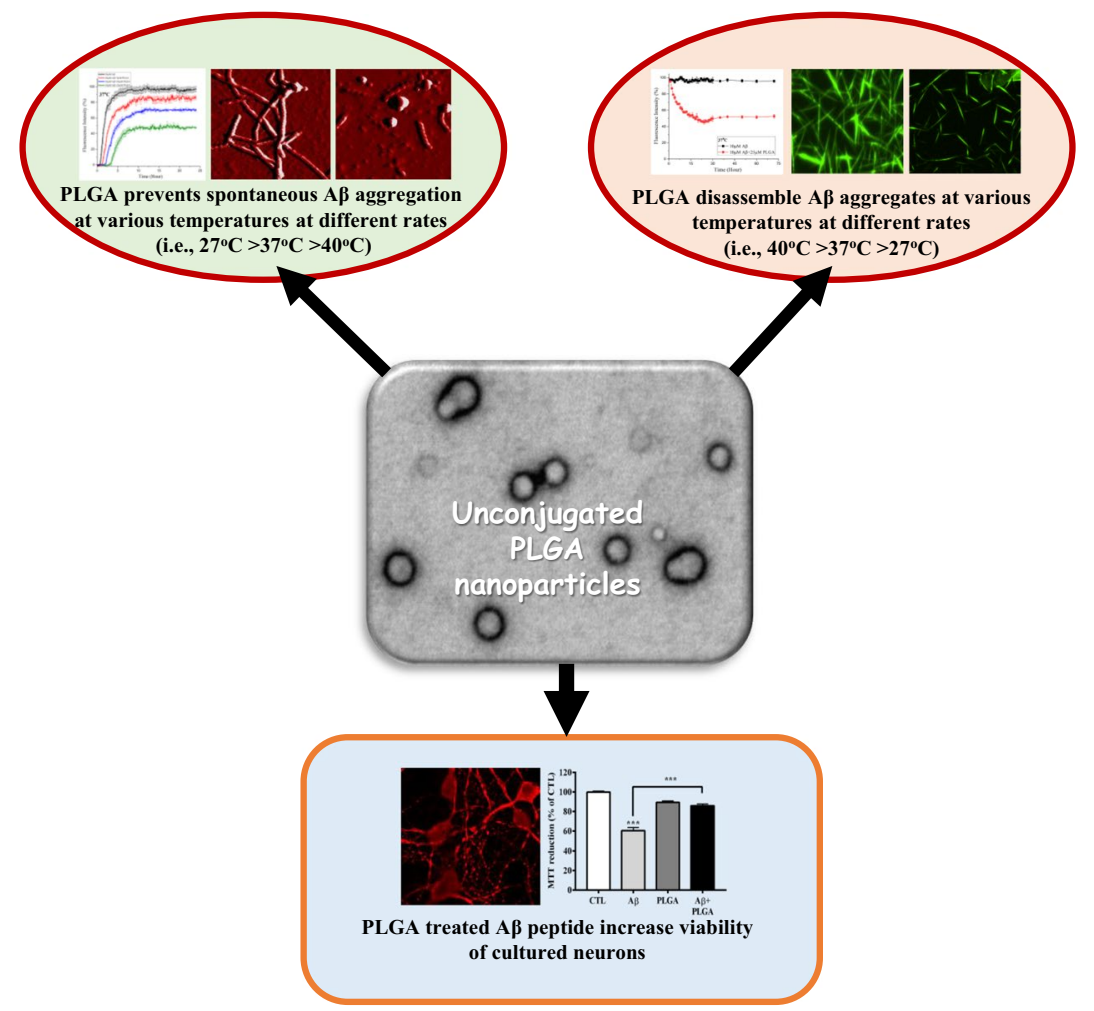

\section{Introduction}

Alzheimer's disease (AD) is an unrelenting neurodegenerative disorder characterized neuropathologically by the presence of tau-positive intracellular neurofibrillary tangles, $\beta$-amyloid (A $\beta$ )-containing extracellular neuritic plaques and the loss of synapses/neurons in selected regions of the brain. Etiologically, only a minority $(<10 \%)$ of $\mathrm{AD}$ cases segregate with mutations of three known genes, whereas the majority of cases are sporadic. Other factors that increase the risk of AD include age, head injury, stress and inheritance of an apolipoprotein E4 genotype [1-3]. Evidence suggests that increased levels of A $\beta$ peptides, generated from amyloid precursor protein, contribute to the loss of neurons and subsequent development of $\mathrm{AD}$ pathology. Although various $\mathrm{A} \beta$ peptides containing 39-43 amino acids are produced in normal conditions, the two most common isoforms found in the brain are $A \beta_{1-40}$ and $A \beta_{1-42}$, of which $A \beta_{1-42,}$, due to its more hydrophobic nature, tends to aggregate faster and is more toxic to neurons than the $A \beta_{1-40}$ [4-7]. The transition of soluble $A \beta$ monomer to the fibrillar form is often linked with the neurotoxicity mediated via site-specific phosphorylation of tau protein and subsequent progression of $\mathrm{AD}$ pathology $[1,3,8,9]$. While the C-terminal domain of $A \beta$ determines the rate of fibril formation, the $\mathrm{N}$-terminal region fosters $\mathrm{A} \beta-\mathrm{A} \beta$ polymerization, leading to a random coil or $\alpha$-helix to $\beta$-sheet transition. The extended $\beta$-sheet promotes $A \beta$ oligomer formation which serves as nuclei for fibril growth and subsequent deposition of $A \beta$ aggregates in neuritic plaques of $A D$ brains $[10,11]$. Over the years, a number of pharmacological and non-pharmacological strategies have been used to interfere with $A \beta$ aggregation/toxicity as potential treatments for $\mathrm{AD}$.

The conformational transition of the $A \beta$ peptide, apart from increased $A \beta$ levels, is known to be influenced by a variety of environmental factors including $\mathrm{pH}$, metal ions, oxidation state, high cholesterol, ionic strength and temperature [12-18]. Temperature, like any other kinetical reaction, facilitates $A \beta$ fibrilization as the velocity of $\mathrm{A} \beta$ aggregation at $25^{\circ} \mathrm{C}$ is reported to be about $10 \%$ of that at $37^{\circ} \mathrm{C}$ [19]. Variation in ambient temperatures has also been shown to influence $A \beta$ levels/aggregation and phosphorylation of tau protein in a variety of cellular and 
animal models of AD [20-24]. Human body temperature, under normal condition, varies in the range from 35 to $39{ }^{\circ} \mathrm{C}$ and increases to $42{ }^{\circ} \mathrm{C}$ during fever [25-27], whereas local temperature in different brain diseases/ tumors fluctuates from 33.4 to $42{ }^{\circ} \mathrm{C}[18,28,29]$. A recent prospective study reveals that high-temperature sauna baths can lower the risk of developing dementia and AD pathology in humans [30]. Although these studies indicate that temperature can influence AD-related pathology, very little is known about how temperature can affect $A \beta$ aggregation or kinetic reaction in the presence of small molecular agents known to attenuate $A \beta$ aggregation/toxicity.

Over the last decade, a number of small molecules including nanoparticles, which are engineered materials less than $100 \mathrm{~nm}$ in diameter with unique physio-chemical properties, have been explored extensively as novel therapeutic modalities to inhibit $A \beta$ aggregation/toxicity. Intrinsic structural and surface properties of nanoparticles such as size, shape, net-charge and surface hydrophobicity regulate their interactions with $A \beta$ peptides [31-35]. Interestingly, acidic poly (D,L-lactide-co-glycolide) (PLGA) nanoparticles, which constitute a family of FDA-approved biodegradable polymers synthesized from glycolic acid and lactic acid, have long been studied as delivery vehicles for a variety of drugs, proteins and other macromolecules. In fact, some earlier studies have shown that PLGA-encapsulated drugs/agents such as donepezil, memantine etc., can have beneficial effects on cellular and/or animal models of $\mathrm{AD}$ with satisfactory biocompatibility [36-41]. More recently, we reported that PLGA nanoparticles without functionalization with any agent/drug can suppress $A \beta$ aggregation/toxicity in cellular and animal models of $\mathrm{AD}[42,43]$. In the present study, we evaluated how hypothermic $\left(27^{\circ} \mathrm{C}\right)$ and hyperthermic $\left(40^{\circ} \mathrm{C}\right)$ conditions can influence spontaneous $\mathrm{A} \beta_{1-42}$ aggregation compared to normal conditions $\left(37^{\circ} \mathrm{C}\right)$. Additionally, we analyzed if unconjugated PLGA can suppress $A \beta_{1-42}$ aggregation/toxicity at hypothermic and hyperthermic conditions as observed in normal condition, thus highlighting the significance of temperature and PLGA in regulating $A \beta$ pathology.

\section{Materials and methods Materials}

Recombinant human $A \beta_{1-42}$ peptide ( $>97 \%$ purity, lyophilized powder) and human $A \beta_{42-1}$ peptide $(>95 \%$ purity, lyophilized powder) were purchased from rPeptide R\&D (Sunnyvale, CA, USA) and Anaspec (Sunnyvale, CA, USA), respectively. PLGA (50:50 resomer; lactic acid:glycolic acid) was from Phosphorex (Hopkinton, MA, USA). Hexafluoro-2-Propanol (HFIP), Thioflavin $\mathrm{T}$ (ThT), dimethyl sulfoxide (DMSO), PLGA
(50:50 and 75:25 resomers; lactic acid:glycolic acid), polycaprolactone (PCL), polyethylene glycol (PEG)PLGA and tetrahydrofuran and 3-(4,5-dimethylthiazol-2-yl)-2,5-diphenyltetrazolium bromide (MTT) were obtained from Sigma-Aldrich (St. Louis Missouri, USA), whereas lactate dehydrogenase (LDH)-based cytotoxicity assay kit was from Promega (Wisconsin, USA). Electron microscopy grids (carbon coated 400 mesh copper grids) and uranyl acid stains were purchased from Electron Microscopy Sciences (PA, USA). Dulbecco's modified Eagle's medium (DMEM), neurobasal medium, Hanks' balanced salt solution (HBSS), fetal bovine serum (FBS) and fluorescein- $A \beta_{1-42}$ were purchased from rPeptide (Watkinsville, USA). Sources of primary antibodies used in the study are listed in Table 1. All horseradish peroxidase-conjugated secondary antibodies were from Bio-Rad Lab (Hercules, CA, USA). All other chemicals were obtained from either Sigma-Aldrich or Thermo Fisher Scientific.

\section{Preparation of $A \beta$ peptides}

Lyophilized $A \beta_{1-42}$ and $A \beta_{42-1}$ stored at $-80{ }^{\circ} \mathrm{C}$ were first equilibrated at room temperature for $30 \mathrm{~min}$ before dissolving in HFIP to obtain a $1 \mathrm{mM}$ solution. Once dissolved, peptide aliquots were quickly dried using a SpeedVac to remove HFIP and then stored at $-80^{\circ} \mathrm{C}$ for subsequent analysis as described previously [44]. On the day of experiment, $A \beta_{1-42}$ aliquot was thawed at $4{ }^{\circ} \mathrm{C}$, diluted with DMSO to obtain $5 \mathrm{mM}$ concentration and then with phosphate-buffer saline (0.01 M PBS, pH 7.4) to $100 \mu \mathrm{M}$ concentration and finally incubated at $4{ }^{\circ} \mathrm{C}$ for $22 \mathrm{~h}$ to get $\mathrm{A} \beta$ oligomers. As for fibril preparation, $\mathrm{A} \beta_{1-42}$ aliquot was diluted to $100 \mu \mathrm{M}$ concentration with $0.01 \mathrm{M} \mathrm{PBS}(\mathrm{pH} 7.4)$ and then incubated at $37^{\circ} \mathrm{C}$ for $24 \mathrm{~h}$ to get $\mathrm{A} \beta$ fibrils. Both $\mathrm{A} \beta$ oligomers and/ or fibrils were then used for experiments in presence or absence of unconjugated PLGA, PEG-PLGA and PCL nanoparticles.

Table 1 Details of the primary antibodies used in this study

\begin{tabular}{llll}
\hline Antibody type & Type & WB/FT dilution & Source \\
\hline Amyloid fibrils OC & Polyclonal & $1: 1000$ & Sigma-Aldrich \\
B-actin & Monoclonal & $1: 5000$ & Sigma-Aldrich \\
Oligomer A11 & Polyclonal & $1: 1000$ & Invitrogen \\
Phospho-ERK & Polyclonal & $1: 1000$ & Cell signaling \\
Phospho-GSK & Polyclonal & $1: 1000$ & Abcam \\
Total-ERK & Monoclonal & $1: 1000$ & Cell signaling \\
Total-GSK & Monoclonal & $1: 1000$ & Abcam \\
Tau (AT270) & Monoclonal & $1: 1000$ & Thermo fisher \\
\hline
\end{tabular}

$W B$ western blotting; $F T$ filter-trap assay 
Preparation of PLGA, PEG-PLGA and PCL nanoparticles

PLGA, PEG-PLGA and PCL nanoparticles were prepared following manufacture's instruction as described previously [42]. In brief, PLGA powder is dissolved into PBS (0.01 M PBS, pH 7.4) followed by sonication using a probe sonicator with 40 pulses and $40 \%$ amplitude, whereas PEG-PLGA and PCL were initially dissolved in tetrahydrofuran and then diluted to required concentrations in PBS buffer.

\section{$A \beta$ aggregation kinetics}

The aggregation kinetics at different concentrations (i.e., 2.5-20 $\mu \mathrm{M}$ ) of $\mathrm{A} \beta_{1-42}$ were carried out in $150 \mu \mathrm{l}$ reaction buffer containing $10 \mathrm{mM} \mathrm{Na} \mathrm{Na}_{2} \mathrm{HPO}_{4}$ with $100 \mathrm{mM} \mathrm{NaCl}(\mathrm{pH} 7.4)$ at $27^{\circ} \mathrm{C}, 37^{\circ} \mathrm{C}$ and $40^{\circ} \mathrm{C}$ in the absence or presence of different concentrations $(5 \mu \mathrm{M}$, $10 \mu \mathrm{M}$ and $25 \mu \mathrm{M})$ of unconjugated PLGA. In parallel, aggregation kinetic of $10 \mu \mathrm{M} \mathrm{A} \beta_{1-42}$ was evaluated with $100 \mathrm{nM}$ PCL, $5 \mu \mathrm{M}$ PEG-PLGA or $25 \mu \mathrm{M}$ unconjugated PLGA (50:50 and 75:25 resomers) obtained from another source. Aggregation of $10 \mu \mathrm{M} \mathrm{A} \beta_{42-1}$ was also studied in absence and presence of unconjugated PLGA as a control. The aggregation process was monitored by ThT binding assay while the concentration of ThT was maintained at $20 \mu \mathrm{M}$ throughout the experiment. The fluorescence signal was measured every $15 \mathrm{~min}$ for $24 \mathrm{~h}$ using a Fluostar omega BMG Labtech (Aylesbury, UK) with excitation at $440 \mathrm{~nm}$ and emission at $480 \mathrm{~nm}$. All kinetic experiments were repeated six times with three technical replicates for each sample/experiment and the data are presented as mean \pm SEM for each condition. Raw data for the experiments were normalized in the form of percentage fluorescence intensity and the graphs were plotted using ORIGIN 2018. The kinetic rate of $A \beta$ fibrillization was determined by fitting the fluorescence intensity versus time according to the Boltzmann curve as described below:

$$
\mathrm{Y}=\frac{\mathrm{F}_{\max }-\mathrm{F}_{0}}{1+\mathrm{e}^{\left(\mathrm{T}-\mathrm{T}_{\mathrm{m}}\right) \times \mathrm{K}}}+\mathrm{F}_{\max }
$$

where " $F_{\max }$ " is the maximum fluorescence intensity and " $\mathrm{F}_{0}$ " is the initial fluorescence intensity, " $\mathrm{K}$ " is the rate constant of fibril elongation and " $\mathrm{T}_{\mathrm{m}}$ " is the time at which fluorescence intensity is at half maximum.

\section{Fluorescence microscopy}

A small aliquot $(10 \mu \mathrm{l})$ of $A \beta_{1-42}$ and $A \beta_{42-1}$ sample in absence and presence of different concentrations of PLGA was added separately on a clean glass slide, airdried and then stained with ThT solution as described earlier [45]. The images of ThT-stained $A \beta_{1-42}$ and
$\mathrm{A} \beta_{42-1}$ aggregates were then captured using a fluorescence microscope (Nikon eclipse $90 \mathrm{i}$ ) at $20 \mathrm{X}$ magnification. In parallel, the fluorescence intensity of the ThT-stained $A \beta_{1-42}$ aggregates in the presence and absence of PLGA at saturation was measured using Image J software.

\section{Scanning transmission electron microscopy (STEM)}

An ultra-high resolution Hitachi S-5500 cold field emission STEM was used to examine the morphological changes of $A \beta_{1-42}$ during aggregation. Initially $5 \mu \mathrm{A} \beta_{1-}$ ${ }_{42}$ samples with or without PLGA were deposited onto plasma cleaned, carbon coated copper grids for $30 \mathrm{~s}$, excess liquid was blotted and the grids were dried and then gently washed with $10 \mu \mathrm{l}$ of Milli-Q water to remove the salt from the PBS solution. The grid was stained with $5 \mu \mathrm{l}$ of $2 \%$ aqueous uranyl acetate for $30 \mathrm{~s}$, blotted to remove excess liquid, dried and then imaged at $30 \mathrm{kV}$ accelerating voltage and $30 \mu \mathrm{A}$ emission current.

\section{Atomic force microscopy (AFM)}

AFM analysis of A $\beta$ samples was performed using Veeco NanoScope IV multimode as described earlier [46]. In brief, $5 \mu \mathrm{L}$ A $\beta$ samples with or without $25 \mu \mathrm{M}$ PLGA treatment were deposited on a freshly cleaved mica sheet $\left(1 \times 1 \mathrm{~cm}^{2}\right)$ by spin-coating at $2500 \mathrm{rpm}$ for $30 \mathrm{~s}$ to remove the excessive precipitation from the surface of the sample. The sample surface was then gently washed with $0.5 \mathrm{ml}$ of Milli-Q water under a sterile, dust free environment to remove the excess molecules and the salt from the PBS solution and finally air dried for 1 day before use. The AFM topography images were captured in tapping mode. To obtain an optimized height profile, silicon cantilevers (MikroMasch USA, Inc.) with low spring constants of $4.5 \mathrm{~N} / \mathrm{m}$ were used in tapping mode (TM-AFM). To obtain a clear image from the surface, a low scan rate $(0.5-1 \mathrm{~Hz})$ and amplitude setpoint $(1 \mathrm{~V})$ were chosen during measurement.

\section{Dynamic light scattering (DLS)}

The size distribution of aggregated $A \beta_{1-42}$ samples in the absence or presence of PLGA, PEG-PLGA and PCL, at the end of the lag phase and/or after reaching saturation (i.e., 24 h), were carried out with a Malvern Zetasizer-Nano Instrument as described earlier [45]. A $\mathrm{He}-\mathrm{Ne}$ laser with a wavelength of $632 \mathrm{~nm}$ was used to detect backscattered light at a fixed angle of $173^{\circ}$. The aggregated samples were prepared by incubating $10 \mu \mathrm{M}$ $\mathrm{A} \beta_{1-42}$ with or without $5 \mu \mathrm{M}, 10 \mu \mathrm{M}$ or $25 \mu \mathrm{M}$ PLGA at $27{ }^{\circ} \mathrm{C}, 37^{\circ} \mathrm{C}$ and $40{ }^{\circ} \mathrm{C}$ under constant shaking. The software (DTS v6.20) provides both the mean size and 
polydispersity by cumulants analysis. The solution viscosity and refractive index (1.33) were assumed to be of water for calculation purposes. Data were collected using a $10 \mathrm{~mm}$ quartz cuvette filled with $150 \mu \mathrm{L}$ sample without agitation from a minimum number of 10 consecutive runs of $10 \mathrm{~s}$ each to obtain the autocorrelation function. Particle size was calculated by the manufacturer's software through the Stokes-Einstein equation assuming spherical particles. In parallel, we used DLS to measure native PLGA's stability as a function of time at different temperatures (i.e., $27^{\circ} \mathrm{C}, 37^{\circ} \mathrm{C}$ and $40{ }^{\circ} \mathrm{C}$ ) as well as in medium used in culturing neurons.

\section{Circular dichroism (CD)}

CD experiments were carried out using a Chirascan circular dichroism spectrometer (Applied photophysics) as described earlier [43]. The CD spectra of aggregated $A \beta_{1-42}$ in the absence or presence of $25 \mu \mathrm{M}$ PLGA (at 1:2.5 ratio) at different temperatures were recorded over a wavelength range of $250-190 \mathrm{~nm}$, by using $0.1 \mathrm{~cm}$ path length quartz cell and each spectrum was averaged using 6 repeat scans. The CD spectra of all samples were measured after reaching saturation (i.e., $24 \mathrm{~h}$ ) to evaluate the effect of PLGA on the aggregation process. Baseline correction was performed by subtracting the spectral contribution of a reaction buffer containing $10 \mathrm{mM} \mathrm{Na}_{2} \mathrm{HPO}_{4}$ and $100 \mathrm{mM} \mathrm{NaCl}$. To retrieve better quantitative structural information, all raw $\mathrm{CD}$ spectra were de-convoluted using the CDPro software.

\section{Isothermal titration calorimetry (ITC)}

The thermodynamics of $A \beta_{1-42}$ and PLGA were studied using a Microcal VP-ITC (Malvern) at $298 \mathrm{~K}$ as described earlier [47]. In brief, $900 \mu \mathrm{M}$ PLGA was injected into the sample cell containing $30 \mu \mathrm{M} \mathrm{A} \beta_{1-42}$. All samples were dissolved in PBS and were degassed at $4{ }^{\circ} \mathrm{C}$ before titration to prevent the possible formation of air bubbles. To correct for the heat of dilution, standard experiments were performed for $A \beta_{1-42}$ in the absence or presence of PLGA, PLGA with PBS and PBS alone. The volume of first injection was $0.4 \mu \mathrm{l}$ and the subsequent injections were $2 \mu \mathrm{l}$ with $120 \mathrm{~s}$ spacing. The reference power was set to $10 \mu \mathrm{cal} / \mathrm{sec}$ in high feedback gain mode and the syringe stirring speed was set to $300 \mathrm{rpm}$. All data were analyzed and fitted by using one binding site in the inbuilt ORIGIN software.

\section{Interaction of different $A \beta$ conformers with PLGA}

Oligomeric and fibrillar $A \beta_{1-42}$ conformers were first prepared as described earlier [48-50], incubated with $25 \mu \mathrm{M}$ PLGA for $24 \mathrm{~h}$ and then processed for the filter-trap analysis using conformer specific $A \beta$ antibodies. In brief, $10 \mu \mathrm{A} A \beta_{1-42}$ samples with or without PLGA were spotted on a nitrocellulose membrane $(0.02 \mu \mathrm{m})$, subjected to vacuum filtration through a 96-well Bio-Dot Microfiltration system, washed with Tris-buffered saline and then incubated at $4{ }^{\circ} \mathrm{C}$ for $12 \mathrm{~h}$ with oligomer specific $\mathrm{A} 11$ as well as aggregate specific $O C A \beta$ antibodies (Table 1 ). The membranes were further washed with buffers, incubated with appropriate horseradish peroxidase-conjugated secondary antibodies (1:5000) and developed with an ECL kit. All blots were examined using a FluorChem E system (Santa Clara, CA, USA) and the images were processed using Image J software.

\section{Mouse cortical neuronal cultures and cell viability}

Timed pregnant BALB/c mice purchased from Charles River (St. Constant, Quebec, Canada) were maintained according to Institutional and Canadian Council on Animal Care guidelines. Primary cortical cultures were prepared from 18-day-old embryos of timed pregnant mice as described previously [51, 52]. In brief, the frontal cortex from pup brains was dissected in Hanks' balanced salt solution supplemented with $15 \mathrm{mM}$ HEPES, 10 units $/ \mathrm{ml}$ penicillin and $10 \mu \mathrm{g} / \mathrm{ml}$ streptomycin and then digested with $0.25 \%$ trypsin-EDTA. The cell suspension was filtered through a cell strainer and plated $\left(1.5 \times 10^{4}\right.$ cells/ $\mathrm{cm}^{2}$ ) on 96-well plates. The cultures were grown at $37{ }^{\circ} \mathrm{C}$ in a $5 \% \mathrm{CO}_{2}$ humidified atmosphere in Neurobasal medium supplemented with B27/N2, $50 \mu \mathrm{M}$ L-glutamine, $15 \mathrm{mM}$ HEPES, 10 units/ml penicillin, $10 \mathrm{mg} /$ $\mathrm{ml}$ streptomycin and 1\% FBS. The medium was replaced 1 day later without FBS and neurons are treated on day 6 after plating. In brief, cultured neurons were first treated with oligomeric 1-20 $\mu \mathrm{M} \mathrm{A} \beta_{1-42}$ for $24 \mathrm{~h}$. In a parallel set of experiment, cultured neurons were co-treated with unconjugated PLGA $(1-25 \mu \mathrm{M})$, PEG-PLGA $(5 \mu \mathrm{M})$ or PCL $(100 \mathrm{nM})$ along with $10 \mu \mathrm{M}$ oligomeric $\mathrm{A} \beta_{1-42}$ for $24 \mathrm{~h}$. Additionally, cultured neurons were treated with $10 \mu \mathrm{M} \mathrm{A} \beta_{1-42}$ aggregates incubated with or without $25 \mu \mathrm{M}$ unconjugated PLGA for $24 \mathrm{~h}$ or $72 \mathrm{~h}$ at $37^{\circ} \mathrm{C}$. The control and treated cultured neurons after $24 \mathrm{~h}$ were

\footnotetext{
(See figure on next page.)

Fig. 1 Aggregation of $A \beta_{1-42}$ at different temperatures. ThT kinetic assays showing the spontaneous aggregation curves and the corresponding fluorescence images of $2.5 \mu \mathrm{M}(\mathbf{A}-\mathbf{D}), 5 \mu \mathrm{M}(\mathbf{E}-\mathbf{H}), 10 \mu \mathrm{M}(\mathbf{I}-\mathbf{L})$ and $20 \mu \mathrm{M}(\mathbf{M}-\mathbf{P}) \mathrm{A} \beta_{1-42}$ over $24 \mathrm{~h}$ incubation at $27^{\circ} \mathrm{C}$ (black), $37^{\circ} \mathrm{C}$ (red) and $40^{\circ} \mathrm{C}$ (blue). Note the aggregation of $\mathrm{A} \beta_{1-42}$ increases as functions of dose and temperature which reach plateaus over time as indicated by ThT fluorescence levels. The fluorescence images of different $A \beta_{1-42}$ concentrations were taken following $24 \mathrm{~h}$ incubation at $27^{\circ} \mathrm{C}, 37^{\circ} \mathrm{C}$ and $40^{\circ} \mathrm{C}$. Rate constant of the kinetic reaction " $\mathrm{K}$ " at different concentrations of $A \beta_{1-42}$ are shown in the inset of respective aggregation kinteic curves
} 

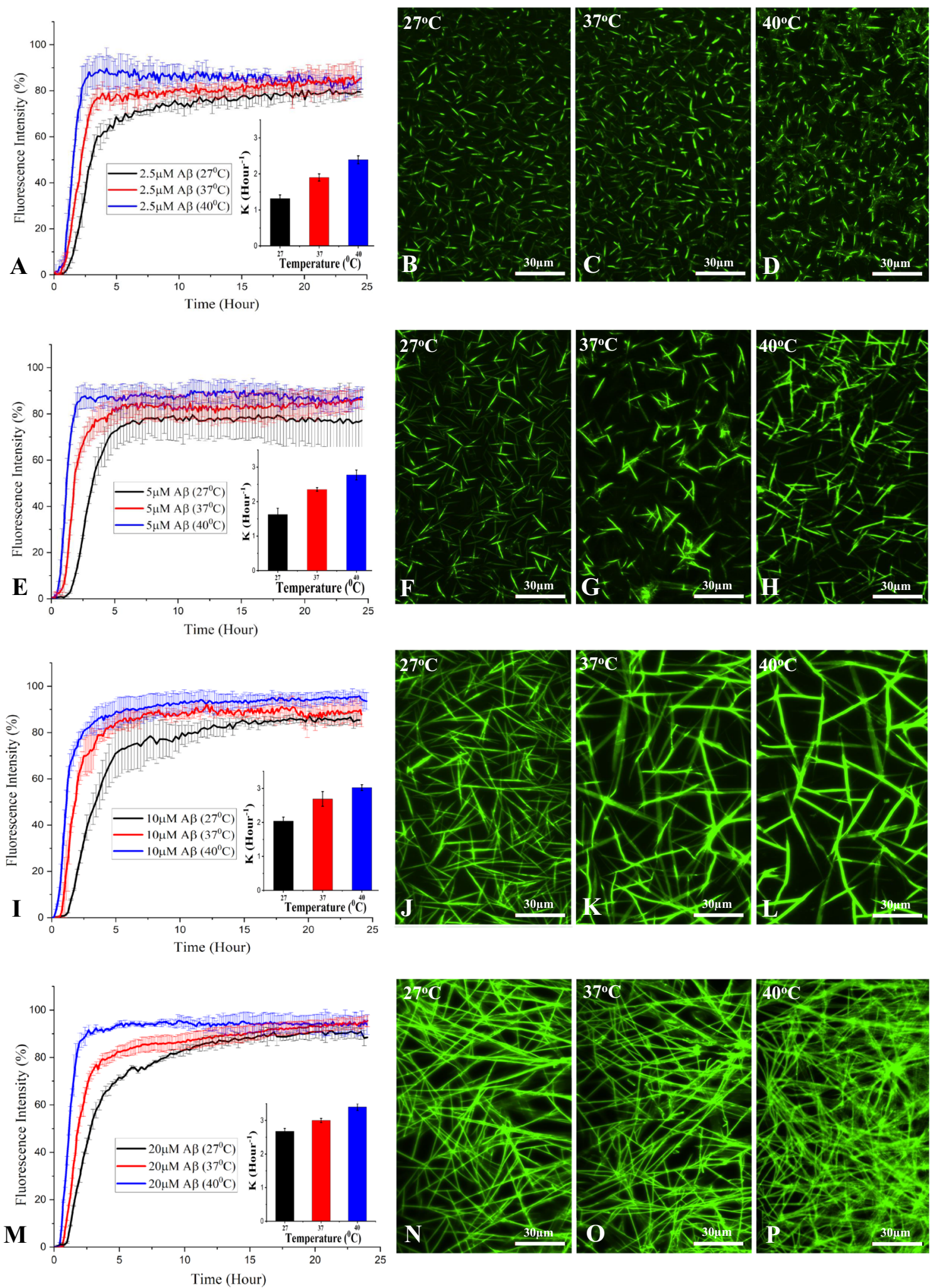

Fig. 1 (See legend on previous page.) 

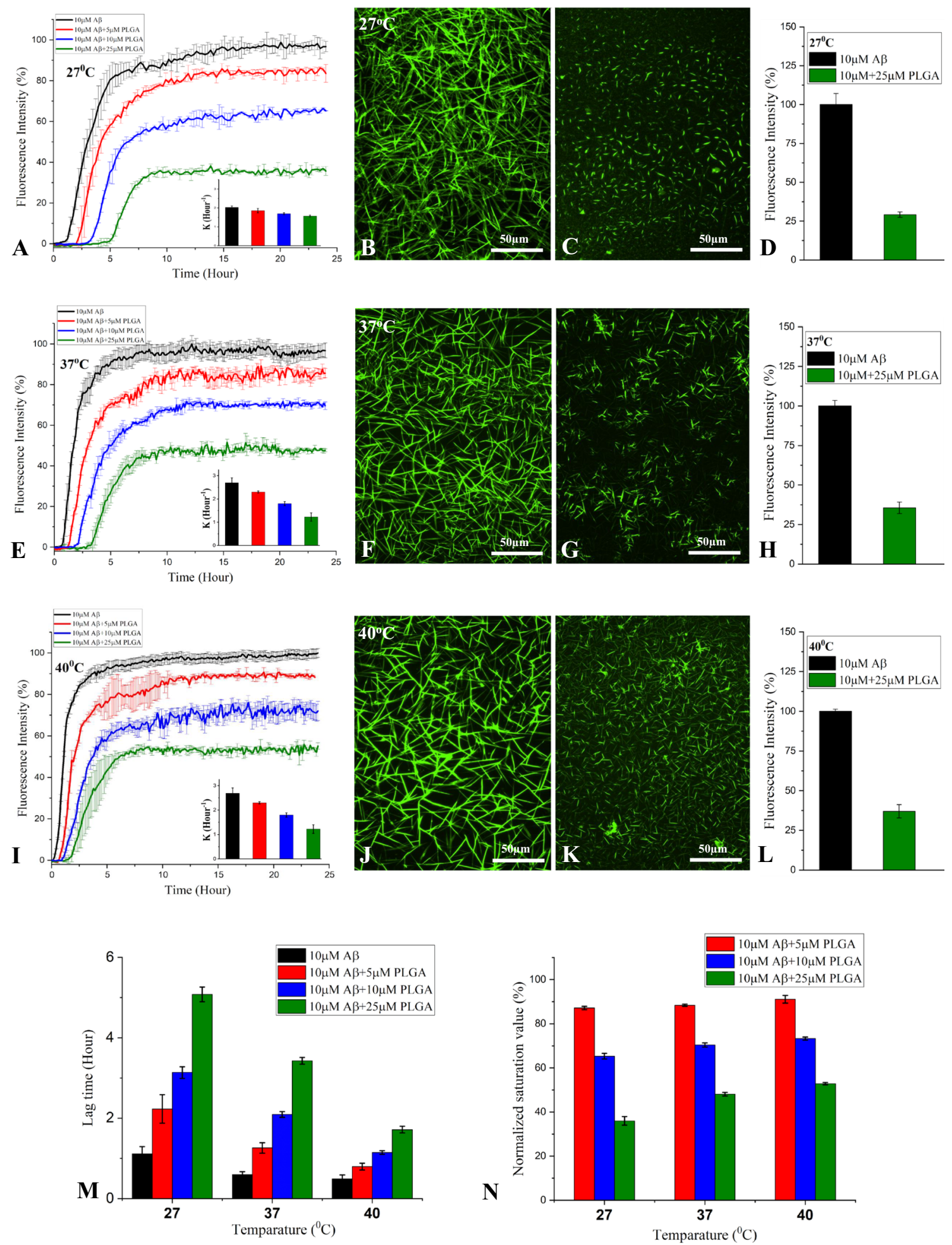

Fig. 2 Attenuation of $A \beta_{1-42}$ aggregation by PLGA at different temperatures. PLGA dose-dependently (5-25 $\mu$ M) attenuates spontaneous aggregation of $10 \mu \mathrm{M} \mathrm{A} \beta_{1-42}$ as revealed by ThT kinetic assays and respective fluorescence images/quantification over $24 \mathrm{~h}$ incubation at $27^{\circ} \mathrm{C}(\mathbf{A}-\mathbf{D}), 37^{\circ} \mathrm{C}(\mathbf{E}-\mathbf{H})$ and $40^{\circ} \mathrm{C}(\mathbf{I}-\mathbf{L})$. The corrosponding rate constant of the kinetic reaction " $\mathrm{K}$ " is shown as inset in each plot. ThT stained fluorescence images $(\mathbf{B}, \mathbf{C}, \mathbf{F}, \mathbf{G}, \mathbf{J}, \mathbf{K})$ and the corresponding quantification $(\mathbf{D}, \mathbf{H}, \mathbf{L})$ of PLGA untreated and treated $A \beta_{1-42}$ samples were taken after $24 \mathrm{~h}$ incubation at $27^{\circ} \mathrm{C}, 37^{\circ} \mathrm{C}$ and $40^{\circ} \mathrm{C}$. Histograms representing the attenuated fluorescence values at lag-time $(\mathbf{M})$ and at saturation $(\mathbf{N})$ of $A \beta_{1-42}$ kinetic reaction in the absence and presence of $5-25 \mu \mathrm{M}$ PLGA at different temperatures 
processed for cell viability/toxicity assays as well as for Western blotting.

\section{Administration of PLGA with or without $A \beta_{1-42}$ into control mouse brains}

To determine if native PLGA can influence the $A \beta_{1-42}$ clearance from the brain, we used normal control mice on C57BL/6 J background. These mice were purchased from The Jackson Laboratory (Bar Harbor, ME, USA) and housed on a $12 \mathrm{~h}$ light/dark cycle with access to food and water ad libitum in accordance with Canadian Council on Animal Care guidelines. Six-month-old control mice ( $\mathrm{n}=3$ /group) were stereotaxically $(-0.2 \mathrm{~mm} \mathrm{mid} /$ lateral, $-1.6 \mathrm{~mm}$ antero/posterior and $-1.2 \mathrm{~mm}$ dorso/ventral from Bregma) injected using Hamilton syringe under anesthesia with either $5 \mu$ l fluorescence labelled $A \beta_{1-42}(10 \mu \mathrm{M})$ followed by CSF or $5 \mu \mathrm{l}$ native PLGA $(25 \mu \mathrm{M})$ [53]. The mice were decapitated after 6 and $24 \mathrm{~h}$ post-injection, their brains were snap-frozen and sectioned $(35 \mu \mathrm{m})$ using a cryostat. The brain sections were then mounted with ProLong $^{\mathrm{TM}}$ gold antifade reagent with DAPI and imaged using a Nikon Eclipse 90i fluorescence microscope equipped with a Retiga 2000R Q imaging system (Nikon Instruments Inc., NY, USA). The fluorescence intensity of labelled $A \beta$ and DAPI was quantified from the acquired photomicrographs using image-J software and the relative fluorescence intensity of $\mathrm{A} \beta$ was calculated as the ratio of $\mathrm{A} \beta \nu$ s corresponding DAPI intensities [54].

\section{Cytotoxicity assays}

The viability of control and treated neurons following various experimental paradigms was determined using the MTT and/or LDH assays as previously described [44, 45]. For the MTT assay, the culture media of the neurons was replaced with new media containing $0.5 \mathrm{mg} / \mathrm{ml} \mathrm{MTT}$, the cells were incubated for $4 \mathrm{~h}$ at $37{ }^{\circ} \mathrm{C}$, the formazan crystals were dissolved in dimethyl sulfoxide and absorbance was measured at $570 \mathrm{~nm}$ with a microplate reader. To substantiate the MTT data, the viability of control and treated cultured neurons was measured using a commercial LDH activity assay kit. The absorbance for $\mathrm{LDH}$ was measured at $490 \mathrm{~nm}$ with a Spectramax M5 spectrophotometer. All cell viability/toxicity experiments were repeated three times with three to five technical replicates per sample.

\section{Western blotting}

Western blotting was performed on control and $A \beta$-treated cultured cells as described earlier [42]. In brief, cultured neurons from various experimental paradigms were homogenized with radioimmunoprecipitation lysis buffer and total protein content was quantified using a BCA kit. Denatured samples were resolved on $10 \%$ polyacrylamide gels, transferred to PVDF membranes, blocked with 5\% milk and incubated overnight at $4{ }^{\circ} \mathrm{C}$ with various primary antibodies at dilutions listed in Table 1 . The membranes were then incubated with horseradish peroxidase-conjugated secondary antibodies (1:5000) and immunoreactive proteins were detected with an ECL kit. All blots were reprobed with anti- $\beta$-actin antibody and quantified using ImageJ as described earlier [55].

\section{Statistical analysis}

All data collected from a minimum of 3 biological repeats with each experiment performed in at least three replicates were expressed as means \pm SEM. The cell viability data from cultured neurons were analyzed by one-way ANOVA followed by Bonferroni's post-hoc analysis for multiple comparisons with a significance threshold set at $p<0.05$. All statistical analysis was performed using GraphPad Prism (GraphPad Software, Inc., CA, USA).

\section{Results}

\section{Effect of temperatures on $A \beta_{1-42}$ aggregation}

Aggregation of $\mathrm{A} \beta$ peptide plays an important role in $\mathrm{AD}$ pathogenesis. Structurally, $A \beta$ fibrils are aggregates with repetitive cross $-\beta$ sheets stabilized by different molecular interactions. The classic dye ThT is normally used in detecting $A \beta$ fibril formation due to its strong fluorescence emission upon binding to cross- $\beta$ fibril structures $[43,44]$. Since temperature is known to influence protein aggregation which underlies the development of AD pathology [17-21], it is of clinical relevance to determine how variation in temperatures can affect spontaneous $A \beta_{1-42}$ aggregation. Thus, we performed ThT kinetic assay by incubating $2.5-$ $20 \mu \mathrm{M}$ human $\mathrm{A} \beta_{1-42}$ at three different temperatures (27, 37 and $40{ }^{\circ} \mathrm{C}$ ) over $24 \mathrm{~h}$ as described earlier (Fig. 1A-P). The aggregation kinetics in all studied conditions exhibited sigmoidal curves with a lag phase and a log phase followed by a saturation phase (Fig. 1A, E, I, M). With increasing

\footnotetext{
(See figure on next page.)

Fig. 3 Attenuation of $A \beta_{1-42}$ aggregation by PLGA as revealed by STEM. A STEM image showing the spherical morphology of unconjugated PLGA nanoparticles without $A \beta$ peptide. STEM images of $10 \mu \mathrm{M} \mathrm{A} \beta_{1-42}$ following $24 \mathrm{~h}$ incubation in the absence (B, D, F) and presence $(\mathbf{C}, \mathbf{E}, \mathbf{G})$ of $25 \mu \mathrm{M}$ PLGA at $27^{\circ} \mathrm{C}(\mathbf{B}, \mathbf{C}), 37^{\circ} \mathrm{C}(\mathbf{D}, \mathbf{E})$ and $40^{\circ} \mathrm{C}(\mathbf{F}, \mathbf{G})$. Note the relative decrease in the amount of $A \beta$ fibrils at different temperatures in presence of $25 \mu \mathrm{M}$ PLGA. STEM images showing higher magnification of $A \beta_{1-42}$ samples in the absence $(\mathbf{H})$ and presence $(\mathbf{I})$ of $25 \mu \mathrm{M}$ PLGA at $37^{\circ} \mathrm{C}$. Note the localization of twisted fibers in the PLGA-treated A $\beta$ sample. PLGA nanoparticles are indicated with arrows
} 


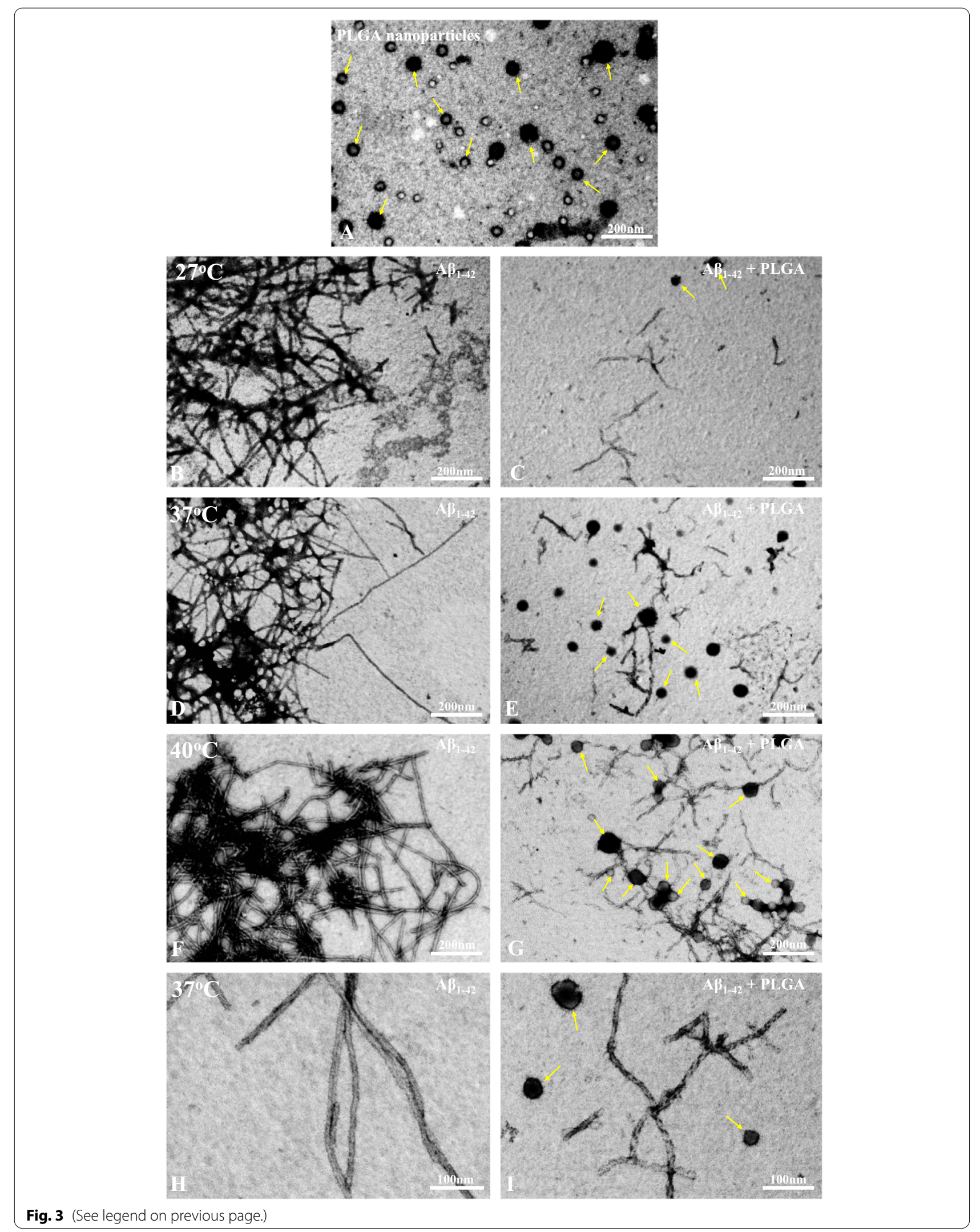


concentrations of $A \beta_{1-42}$ from 2.5 to $20 \mu \mathrm{M}$ at a particular temperature, the rate and amount of fibril formation increases as is evident from the corresponding ThT fluorescence values at the saturation level (Fig. 1, Additional file 1: Fig. S1). These results reflect the general law of aggregation where an increase in the concentration of an amyloidogenic protein is known to enhance its aggregation as a function of time. Similarly, the aggregation rate of $A \beta_{1-42}$ at a given concentration also increases with a rise in temperature from 27 to $40{ }^{\circ} \mathrm{C}$ (insets in Fig. 1A, E, I, M). This is simply because time taken to form fibrils decreases with a rise in temperature due to an increase in the rate of thermal effective collisions. This is apparent more at 5, 10 and $20 \mu \mathrm{M}$ than $2.5 \mu \mathrm{M} \mathrm{A} \beta_{1-42}$ over a $24 \mathrm{~h}$ incubation period. Interestingly, unlike concentrations, the rise in temperature displays marginal changes in the ThT fluorescence value at saturation indicating no drastic alterations in the formation of total fibrils for a given $A \beta_{1-42}$ concentration at different temperatures. The propensity of $A \beta$ aggregation at saturation was further validated by fluorescence imaging of ThT labelled samples which showed a dose-dependent increase of fibrillar $A \beta$ entities at a given temperature. Formation of fibrils also increases as a function of temperature for a given concentration of $A \beta_{1-42}$ (Fig. 1B-D, F-H, J-L, N-P). In contrast to normal $\mathrm{A} \beta_{1-42}, 10 \mu \mathrm{M} \mathrm{A} \beta_{42-1}$ (i.e., a negative control) did not aggregate either at 27,37 or $40{ }^{\circ} \mathrm{C}$ during $24 \mathrm{~h}$ incubation period (Additional file 1: Fig. S2).

\section{Effects of PLGA on temperature-dependent spontaneous $A \beta_{1-42}$ aggregation}

Prior to determining the effects of unconjugated PLGA on temperature-dependent $A \beta$ aggregation, we showed that PLGA nanoparticles, as observed in STEM and AFM, displayed spheroidal morphology. Our DLS analysis further revealed that PLGA with diameter $\sim 100 \mathrm{~nm}$ is quite stable over $48 \mathrm{~h}$ period at 27,37 and $40{ }^{\circ} \mathrm{C}$ (Additional file 1: Fig. S3A-F). The effects of $5-25 \mu \mathrm{M}$ unconjugated PLGA on aggregation kinetics of $10 \mu \mathrm{M} \mathrm{A} \beta_{1-42}$ at 27,37 and $40{ }^{\circ} \mathrm{C}$ were subsequently evaluated over a $24 \mathrm{~h}$ period using the ThT assay. Our data clearly show that PLGA dose-dependently inhibited spontaneous $A \beta_{1-42}$ aggregation at all temperatures (Fig. $2 \mathrm{~A}-\mathrm{N}$ ). At the low concentration of $5 \mu \mathrm{M}$ (i.e., PLGA:A $\beta=1: 2$ ), PLGA displayed only a slight inhibitory effect on $A \beta$ aggregation at different temperatures, whereas $10 \mu \mathrm{M}$ PLGA (i.e., PLGA:A $\beta=1: 1$ ) noticeably attenuated $A \beta$ aggregation at various temperatures relative to that of pure $A \beta$.
When the PLGA concentration was increased to $25 \mu \mathrm{M}$ (i.e., PLGA:A $\beta=2.5: 1$ ) a much stronger inhibition was observed at all temperatures, with a reduction of $\sim 65 \%$ at $27{ }^{\circ} \mathrm{C}, \sim 52 \%$ at $37{ }^{\circ} \mathrm{C}$ and $\sim 48 \%$ at $40{ }^{\circ} \mathrm{C}$ in the saturation phase over the $24 \mathrm{~h}$ incubation (Fig. 2A, E, I, N). Increasing concentrations of PLGA were found to prolong the lag time and decrease the rate of $A \beta$ fibrilization at all temperatures, but this effect is more pronounced at $27{ }^{\circ} \mathrm{C}$ than at higher temperatures (Fig. 2A, E, I, M). Suppression of $A \beta_{1-42}$ aggregation at saturation by 5 or $10 \mu \mathrm{M}$ PLGA, as apparent from ThT kinetic assays, did not display striking effects as a function of temperature. However, $25 \mu \mathrm{M}$ PLGA inhibited $\mathrm{A} \beta$ aggregation more profoundly at $27^{\circ} \mathrm{C}$ than at 37 or $40{ }^{\circ} \mathrm{C}$ over a $24 \mathrm{~h}$ incubation period (Fig. $2 \mathrm{~N}$ ). The inhibitory effect of PLGA on spontaneous $A \beta_{1-42}$ aggregation at saturation is further validated by fluorescence imaging which showed respectively fewer $A \beta$ fibrillar entities in the presence of PLGA (Fig. 2B-D, F-H, J-L) with a corresponding decrease in temperatures from 40 to $27{ }^{\circ} \mathrm{C}$ (i.e., $37 \%$ at $40{ }^{\circ} \mathrm{C}, 35 \%$ at $37^{\circ} \mathrm{C}$ and $29 \%$ at $27^{\circ} \mathrm{C}$ ).

To delve into the structural details of $\mathrm{A} \beta$ aggregates in the presence or absence of $25 \mu \mathrm{M}$ PLGA after $24 \mathrm{~h}$ incubation, we used STEM (Fig. 3A-I) and AFM (Fig. 4A-F) to examine aggregate morphology at higher resolution. Our data revealed that PLGA nanoparticles, which displayed spheroidal morphology with an average diameter of $\sim 100 \mathrm{~nm}$ (Figs. 3A; 4A, B), are associated directly with $A \beta_{1-42}$ fibers and attenuate peptide aggregation, leading to the formation of a heterogenous mixture of smaller $A \beta$ aggregates (Figs. 3B-I; $4 \mathrm{C}-\mathrm{F}$ ). The population of $A \beta$ fibers/aggregates, as revealed by our STEM images, decreases at all studied temperatures but is more evident at lower temperature than at higher temperature (Fig. 3B-I). At the structural level, A $\beta$ fibrils after $24 \mathrm{~h}$ incubation without PLGA appear mostly as aggregated long straight and twisted fibers which increase in number with the rise of temperature. Conversely, the PLGA treated $A \beta$ sample shows short, twisted fibers as well as small globular spherical aggregates without any filamentous structure (most likely $\mathrm{A} \beta$ oligomers) (Fig. $3 \mathrm{C}$, E, G, I). With the rise of temperature from 27 to $40{ }^{\circ} \mathrm{C}$, the population of twisted fibers increases with a concomitant decrease in small globular aggregates (Fig. 3C, E, G, I)-suggesting a possible shift/formation of more twisted fibers. Our AFM analysis, apart from two populations (Fig. 4C-F), reveals additional structural differences

(See figure on next page.)

Fig. 4 Attenuation of $A \beta_{1-42}$ aggregation by PLGA as revealed by AFM. AFM images in height (A) and amplitude (B) modes showing spherical morphology of unconjugated PLGA nanoparticles without $A \beta$ peptide. AFM images in height $(\mathbf{C}, \mathbf{D})$ and amplitude $(\mathbf{E}, \mathbf{F})$ modes of $10 \mu M$ A $\beta_{1-42}$ following $24 \mathrm{~h}$ incubation in the absence $(\mathbf{C}, \mathbf{E})$ and presence $(\mathbf{D}, \mathbf{F})$ of $25 \mu \mathrm{M} \mathrm{PLGA}$ at $37^{\circ} \mathrm{C}$. Note the formation and structural details of different populations of smaller aggregates such as short twist fibrils and oligomers in presence of $25 \mu M$ PLGA compared to untreated control A $\beta_{1-42}$. PLGA nanoparticles are highlighed with arrows 

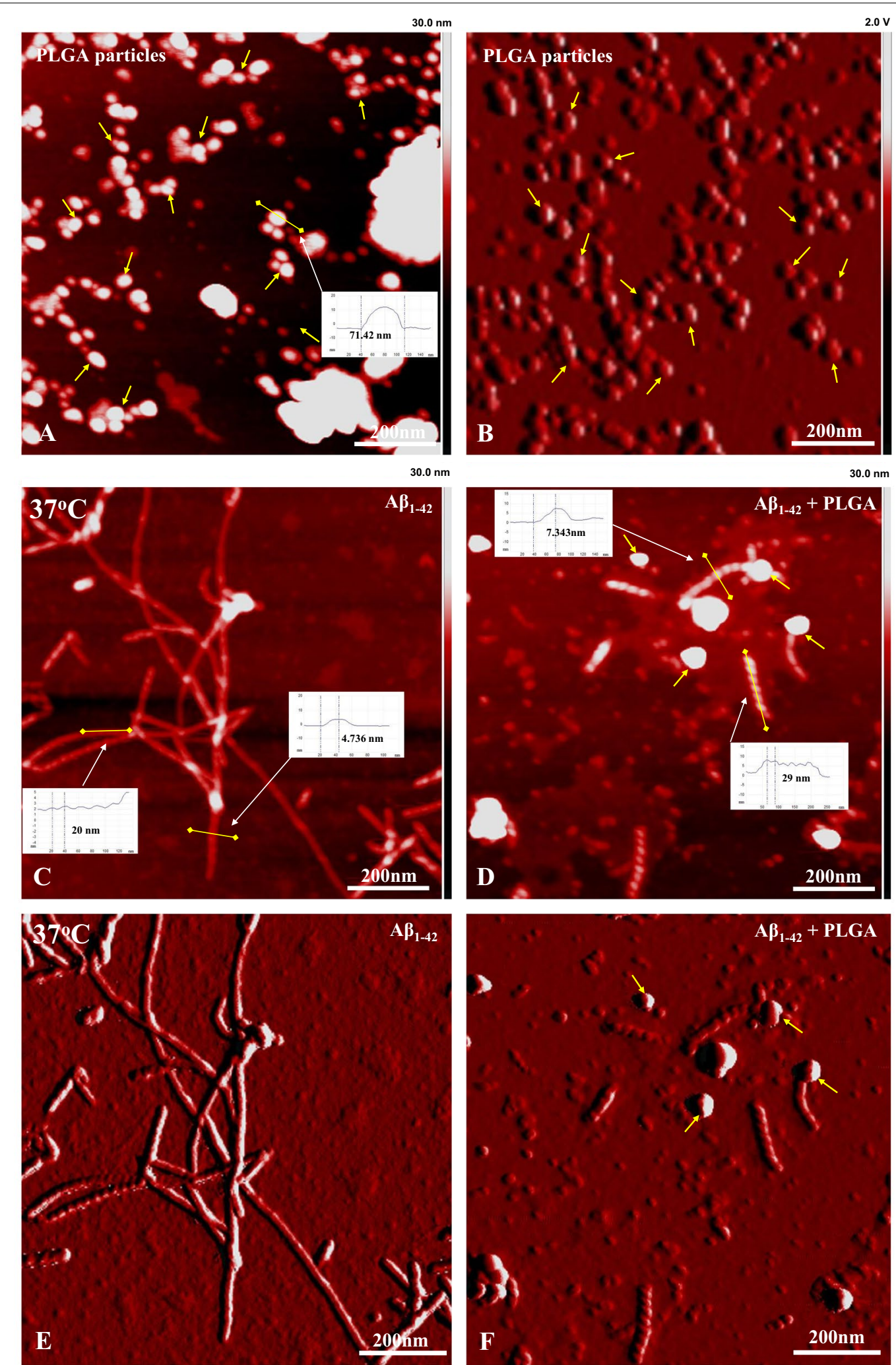

Fig. 4 (See legend on previous page.) 
of $A \beta$ aggregates in the absence and presence of PLGA in both height (Fig. 4C, D) and amplitude (Fig. 4E, F) modes. The untreated control A $\beta$ fibers showed a helical pitch of $\sim 20 \mathrm{~nm}$ and a height of $\sim 4.7 \mathrm{~nm}$ from the surface, whereas the PLGA-treated samples show short, twisted fibrils with a $\sim 29 \mathrm{~nm}$ helical pitch and $\sim 7.3 \mathrm{~nm}$ in height from the surface (Fig. 4C-F). This alteration raises the possibility that PLGA may trigger loosening of molecular packing and intermolecular interaction between intertwined protofilaments/fibrils leading to the formation of short fibrillar structures.

To further validate an overall reduction in the fibrillar size/entities following PLGA treatment, we performed DLS analysis of A $\beta$ samples with or without PLGA following aggregation kinetic assays. Our results indeed showed a reduction in hydrodynamic radii of $A \beta$ aggregates with multiple peaks at all temperatures as a function of PLGA concentrations, but the effect was more profound at $27^{\circ} \mathrm{C}$ than at 37 or $40^{\circ} \mathrm{C}$ over $24 \mathrm{~h}$ incubation (Fig. 5A, B, D, E, G, H). To better understand the internal architecture which transforms the long fibrils to shorter species, we performed CD spectroscopy of A $\beta$ samples with or without PLGA treatment after $24 \mathrm{~h}$ incubation. Consistent with earlier results [43], the far-UV CD spectra of $A \beta_{1-42}$ fibrils after $24 \mathrm{~h}$ at different temperatures showed characteristic $\beta$-sheet conformation with minima around $216 \mathrm{~nm}$ (Fig. 5C, F, I), suggesting the presence of $\beta$-sheet rich secondary structures. Although the nature of the secondary structure of $A \beta_{1-42}$ fibrils remains same at all temperatures, the $\beta$-sheet content, as revealed by deconvolution of $\mathrm{CD}$ spectra, increases with temperature in monotonic order of efficacy i.e., $40{ }^{\circ} \mathrm{C}>37{ }^{\circ} \mathrm{C}>27^{\circ} \mathrm{C}$ (Table 2). In contrast to $A \beta_{1-42}$ alone, the presence of PLGA enhanced the $\alpha$-helical and decreased $\beta$-sheet contents at all temperatures (Fig. 5C, F, I). The reciprocity of $\alpha$-helicity vs $\beta$-sheet content correlates positively as a function of temperature increase from 27 to $40{ }^{\circ} \mathrm{C}$ as shown in Table 2. Our ITC experiments involving titration of native PLGA to a solution containing $A \beta_{1-42}$ showed an exothermic isotherm profile with a binding constant, $\mathrm{K}=1.15 \times 10^{6} \mathrm{M}^{-1}$ and a stoichiometry of $\sim 3$ $(\mathrm{N}=3.07)$. The Gibbs free energy $\Delta \mathrm{G}$ was found to be
- 8. $31 \mathrm{kcal} . \mathrm{M}^{-1}$ with an Enthalpy $(\Delta \mathrm{H})=-4.098 \mathrm{kcal}$. $\mathrm{M}^{-1}$ and an Entropy $(\Delta S)=0.014 \mathrm{kcal} \cdot \mathrm{M}^{-1} \cdot \mathrm{K}^{-1}$ (Fig. 5J).

The inhibitory effects of PLGA on spontaneous $A \beta_{1-42}$ aggregation appear to be mediated by a decreased fibrilization rate and increased lag time which ensue as a function of temperature in the following order of efficacy i.e., $27{ }^{\circ} \mathrm{C}>37{ }^{\circ} \mathrm{C}>40{ }^{\circ} \mathrm{C}$ (Fig. $6 \mathrm{~A}-\mathrm{C}$ ). This is supported by a decreased population of $\mathrm{A} \beta$ fibers/aggregates observed in the presence of $25 \mu \mathrm{M}$ PLGA at $27^{\circ} \mathrm{C}$ than at higher temperatures using STEM (Fig. 6D-I). Our DLS analysis also revealed a mean size reduction in the hydrodynamic radii of $A \beta$ aggregates in the presence of increasing concentrations of PLGA during the lag phase of $A \beta$ aggregation (Fig. 6J-O). The decreased population of $A \beta$ fibers/aggregates is though evident at all temperatures in the presence of PLGA, it is predominant at $27^{\circ} \mathrm{C}$ than at higher temperatures (i.e., 37 or $40^{\circ} \mathrm{C}$ ) (Fig. $6 \mathrm{M}-\mathrm{O}$ ).

\section{Effects of different PLGA resomer, PEG-PLGA and PCL on temperature-dependent spontaneous $A \beta_{1-42}$ aggregation}

To determine if PLGA with 50:50 resomer composition from another source can suppress $A \beta_{1-42}$ aggregation at different temperatures $\left(27,37\right.$ and $\left.40{ }^{\circ} \mathrm{C}\right)$, we performed ThT kinetic assays as well as DLS analysis using $10 \mu \mathrm{M} \mathrm{A} \beta_{1-42}$ in the presence or absence of $25 \mu \mathrm{M}$ PLGA obtained from Sigma-Aldrich (Fig. 7A-I). Our data clearly revealed that 50:50 resomer PLGA from Sigma, as observed with Phosphorex, can suppress aggregation of $\mathrm{A} \beta$ peptides at all temperatures but the effect is more profound at $27{ }^{\circ} \mathrm{C}$ than at 37 or $40{ }^{\circ} \mathrm{C}$ over a $24 \mathrm{~h}$ incubation (Fig. 7A, D, G). This is further validated by DLS analysis which showed a reduction in diameter of $A \beta$ aggregates in presence of $25 \mu \mathrm{M}$ PLGA in the following order of efficacy i.e., $27^{\circ} \mathrm{C}>37^{\circ} \mathrm{C}>40{ }^{\circ} \mathrm{C}$ (Fig. 7B, C, E, F, H, I). However, equimolar PLGA with 75:25 resomer composition did not alter $\mathrm{A} \beta_{1-42}$ aggregation as evident by ThT kinetic assay or DLS analysis (Fig. 7A-I). As a follow up to these results, we evaluated if other polymorphic nanoparticles such as PEG-PLGA and PCL can suppress $A \beta_{1-42}$ aggregation [56, 57]. For this experiment we used $5 \mu \mathrm{M}$ PEG-PLGA and $100 \mathrm{nM}$ PCL as they were found to protect neurons against toxicity following $24 \mathrm{~h}$

\footnotetext{
(See figure on next page.)

Fig. 5 PLGA changes size and secondary structure of $A \beta_{1-42}$ aggregates. DLS analysis $(\mathbf{A}, \mathbf{B}, \mathbf{D}, \mathbf{E}, \mathbf{G}, \mathbf{H})$ and $C D$ spectra $(\mathbf{C}, \mathbf{F}, \mathbf{I})$ of $10 \mu M A \beta_{1-42}$ in the presence and absence of PLGA following $24 \mathrm{~h}$ incubation at $27^{\circ} \mathrm{C}(\mathbf{A}-\mathbf{C}), 37^{\circ} \mathrm{C}(\mathbf{D}-\mathbf{F})$ and $40^{\circ} \mathrm{C}(\mathbf{G}-\mathbf{I})$. DLS analysis reveals a differential decrease in the diameter of $\mathrm{A} \beta_{1-42}$ in the presence of $5 \mu \mathrm{M}(\mathrm{red}), 10 \mu \mathrm{M}$ (blue) and $25 \mu \mathrm{M}$ (green) PLGA incubation at $27^{\circ} \mathrm{C}(\mathbf{A}, \mathbf{B}), 37^{\circ} \mathrm{C}(\mathbf{D}, \mathbf{E})$ and $40{ }^{\circ} \mathrm{C}(\mathbf{G}$, $\mathbf{H}$ ) compared to control $A \beta_{1-42}$ (black) as depicted by size distribution curves and avearge size histograms. PLGA nanoparticles (violet) without exposure to $A \beta$ peptide have also been represented in the corresponding graphs. CD spectra showing $\beta$-sheet content following incubation of $10 \mu \mathrm{M} \mathrm{A} \beta_{1-42}$ in the absence (black) and presence (red) of $25 \mu \mathrm{M}$ PLGA after $24 \mathrm{~h}$ incubation at $27(\mathbf{C}), 37(\mathbf{F})$ and $40{ }^{\circ} \mathrm{C}(\mathbf{I})$, respectively. Note the decreased formation of $\beta$-sheet rich secondary in the presence of PLGA which increases with the rise of temperature. (J) ITC binding isotherms showing interaction between PLGA and $A \beta_{1-42}$ at $25^{\circ} \mathrm{C}$. The top panel shows the differential power signal measured for each injection throughout the experiment and the bottom panel shows the integrated peak areas corresponding to the measured heat released per injection. The thermodynamic parameters for the protein and ligand interaction are shown in the adjacent table
} 

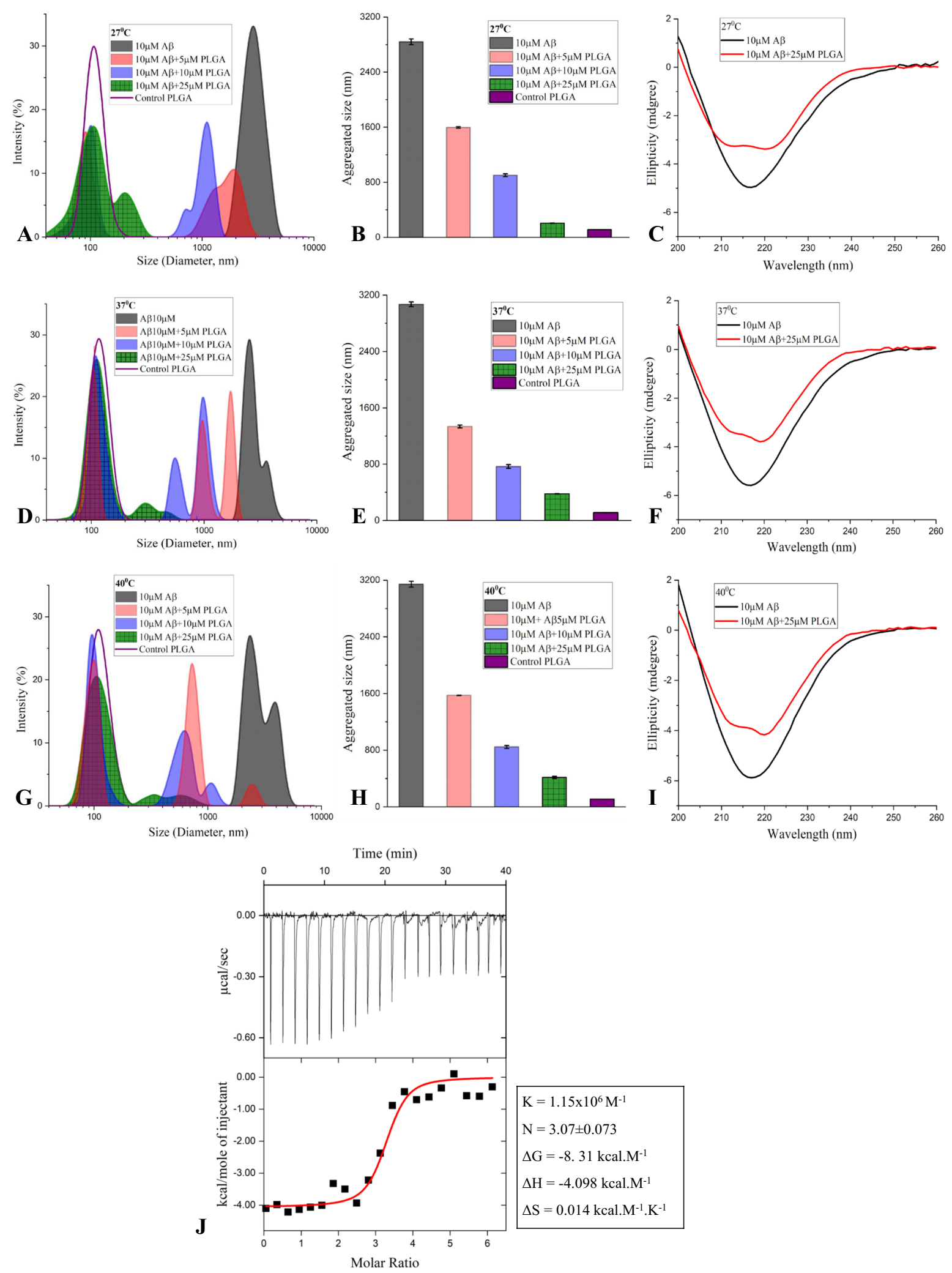

$\mathrm{K}=1.15 \times 10^{6} \mathrm{M}^{-1}$

$\mathrm{N}=3.07 \pm 0.073$

$\Delta \mathrm{G}=-8.31 \mathrm{kcal}^{\mathrm{M}} \mathrm{M}^{-1}$

$\Delta \mathrm{H}=-4.098 \mathrm{kcal} . \mathrm{M}^{-1}$

$\Delta \mathrm{S}=0.014 \mathrm{kcal} . \mathrm{M}^{-1} . \mathrm{K}^{-1}$

Fig. 5 (See legend on previous page.) 
Table 2 CD spectroscopy data depicting a-helical and $\beta$-sheet contents following $24 \mathrm{~h}$ aggregation of $10 \mu \mathrm{M} A \beta_{1-42}$ at different temperatures in the absence and presence of $25 \mu \mathrm{M}$ unconjugated PLGA

\begin{tabular}{lll}
\hline & a-helical content (\%) & $\begin{array}{l}\beta \text {-sheet } \\
\text { content } \\
(\%)\end{array}$ \\
\hline$A \beta_{1-42}\left(27^{\circ} \mathrm{C}\right)$ & 2 & 39 \\
$A \beta_{1-42}\left(37^{\circ} \mathrm{C}\right)$ & 2 & 42 \\
$A \beta_{1-42}\left(40^{\circ} \mathrm{C}\right)$ & 2.1 & 46 \\
$A \beta_{1-42}+P L G A\left(27^{\circ} \mathrm{C}\right)$ & 24 & 32 \\
$A \beta_{1-42}+P L G A\left(37^{\circ} \mathrm{C}\right)$ & 20 & 36 \\
$A \beta_{1-42}+P L G A\left(40^{\circ} \mathrm{C}\right)$ & 18 & 39 \\
\hline
\end{tabular}

exposure to $10 \mu \mathrm{M} A \beta_{1-42}$ (Additional file 1: Fig. S4A, B). Interestingly, both $5 \mu \mathrm{M}$ PEG-PLGA and $100 \mathrm{nM}$ PCL suppress to some extent spontaneous $\mathrm{A} \beta_{1-42}$ aggregation at 27,37 or $40{ }^{\circ} \mathrm{C}$ over a $24 \mathrm{~h}$ incubation period but the effect is much less potent than those observed with native PLGA. This is evident both in ThT kinetic assay and DLS analysis (Fig. 8A-I). These data indicate the specificity of the effects mediated by 50:50 resomer of PLGA which is commonly used in various biological experiments.

\section{Effects of PLGA on different $A \beta$ conformers}

To validate the interaction between PLGA and A $\beta$ peptide, oligomeric and fibrillar $A \beta_{1-42}$ were first prepared as described earlier [47-49]. Subsequently, oligomeric and fibrillar $A \beta_{1-42}$ was incubated with $25 \mu \mathrm{M}$ unconjugated PLGA for $24 \mathrm{~h}$ and then probed with conformer-specific A11 and OC A $\beta$ antibodies using filter-trap assay. Our results clearly demonstrate that PLGA interacted with both conformers of $A \beta_{1-42}$, but its binding to $A \beta$ aggregates was somewhat more apparent than $A \beta$ oligomers under the given experimental conditions (Fig. 8J, K).

\section{Effects of PLGA on temperature-dependent $A \beta_{1-42}$ disassembly}

To establish if PLGA can promote disassembly of mature $A \beta$ fibers at different temperatures, preformed $A \beta_{1-42}$ fibers were incubated with $25 \mu \mathrm{M}$ PLGA for $72 \mathrm{~h}$ at various temperatures (i.e., 27, 37 and $40{ }^{\circ} \mathrm{C}$ ). Our ThT kinetic assay revealed that matured $A \beta_{1-42}$ fibers can initially be dismantled by PLGA in a time-dependent manner at all temperatures and then remained stable over $72 \mathrm{~h}$ incubation period. The dissociation rate is found to be somewhat faster with increasing temperatures, albeit the relative levels of disassembled $A \beta$ fibers at the end of incubation did not exhibit marked variation between temperatures (i.e., $\sim 52 \%$ at $27{ }^{\circ} \mathrm{C}, \sim 53 \%$ at $37{ }^{\circ} \mathrm{C}$ and $\sim 55 \%$ at $40{ }^{\circ} \mathrm{C}$ ) (Fig. $9 \mathrm{~A}-\mathrm{C}$ ). This is supported by fluorescence imaging $\left(32 \%\right.$ at $27{ }^{\circ} \mathrm{C}, 33 \%$ at $37{ }^{\circ} \mathrm{C}$ and $34 \%$ at $40{ }^{\circ} \mathrm{C}$, Fig. 9D-L) as well as STEM (Fig. 9M-R) data showing comparable presence of smaller $A \beta$ fragments after $72 \mathrm{~h}$ PLGA treatment at all temperatures. Dismantling of $A \beta_{1-42}$ fibers is also apparent by DLS at 27, 37 and $40{ }^{\circ} \mathrm{C}$ following $72 \mathrm{~h}$ PLGA treatment with a shift towards the lower ordered entities (diameter $\sim 100$ $600 \mathrm{~nm}$ ) compared with untreated $A \beta_{1-42}$ fibers (diameter 1000-8000 nm) (Fig. 9S-U).

\section{PLGA-mediated attenuation of $A \beta$ aggregation protects cultured neurons}

In keeping with earlier data [11, 42, 49, 58, 59], we showed that exposure of mouse cortical cultured neurons to oligomeric $A \beta_{1-42}$ over $24 \mathrm{~h}$ can induce toxicity in a concentration-dependent manner, as evident from a reduction in MTT values (Fig. 10A). This was validated by a time-dependent increase in LDH levels in the conditioned media (Fig. 10B). Our DLS analysis revealed that unconjugated PLGA is quite stable in culture media over a $48 \mathrm{~h}$ period at $37^{\circ} \mathrm{C}$ (Additional file 1: Fig. S3G-I). Subsequently, we showed that co-treatment of cultured neurons with $10 \mu \mathrm{MA} \beta_{1-42}$ and $25 \mu \mathrm{M}$ PLGA for $24 \mathrm{~h}$ was able to significantly protect neurons against toxicity (Fig. 10C, D). Additionally, we revealed that neurons treated with $10 \mu \mathrm{M} \mathrm{A} \beta_{1-42}+25 \mu \mathrm{M}$ PLGA incubated for $24 \mathrm{~h}$ at $37^{\circ} \mathrm{C}$ prior to neuronal exposure can markedly increase neuronal viability when compared to treatment with $10 \mu \mathrm{MA} \beta_{1-42}$ alone (Fig. 10E, F). In parallel, we noted that $A \beta$ fibers disassembled following $72 \mathrm{~h}$ treatment with PLGA at $37{ }^{\circ} \mathrm{C}$ could significantly increase viability of cultured neurons compared to unaltered A $\beta$ fibers (Fig. 10G-H). The protective effects of PLGA against $\mathrm{A} \beta$-induced toxicity are accompanied by an

(See figure on next page.)

Fig. 6 PLGA alters the lag phase of $A \beta_{1-42}$ aggregation kinetics at different temperatures. ThT kinetic assay showing aggregation of $10 \mu M A \beta_{1-42}$ in the absence and presence of $5-25 \mu \mathrm{M}$ of PLGA over $5 \mathrm{~h}$ incubation (lag phase) at $27^{\circ} \mathrm{C}(\mathbf{A}), 37^{\circ} \mathrm{C}(\mathbf{B})$ and $40^{\circ} \mathrm{C}(\mathbf{C})$. Note the decreased duration of the lag phase with rise in temperature in the absence and presence of presence of PLGA. STEM images of $10 \mu M$ A $\beta_{1-42}$ in the absence (D-F) and presence of $25 \mu \mathrm{M}$ PLGA $(\mathbf{G}-\mathbf{I})$ after $5 \mathrm{~h}$ incubation at $27^{\circ} \mathrm{C}(\mathbf{D}, \mathbf{G}), 37^{\circ} \mathrm{C}(\mathbf{E}, \mathbf{H})$ and $40^{\circ} \mathrm{C}(\mathbf{F}, \mathbf{I})$. Note the attenuation of $A \beta$ fibril formation in the

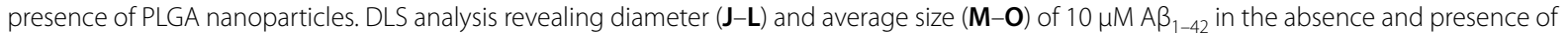
$25 \mu \mathrm{M}$ PLGA after $5 \mathrm{~h}$ incubation at $27^{\circ} \mathrm{C}(\mathbf{J}, \mathbf{M}), 37^{\circ} \mathrm{C}(\mathbf{K}, \mathbf{N})$ and $40^{\circ} \mathrm{C}(\mathbf{L}, \mathbf{O})$. Note the attenuation of $A \beta$ aggregation at different temperatures as a function of PLGA concentrations. PLGA nanoparticles are highlighed with arrows 

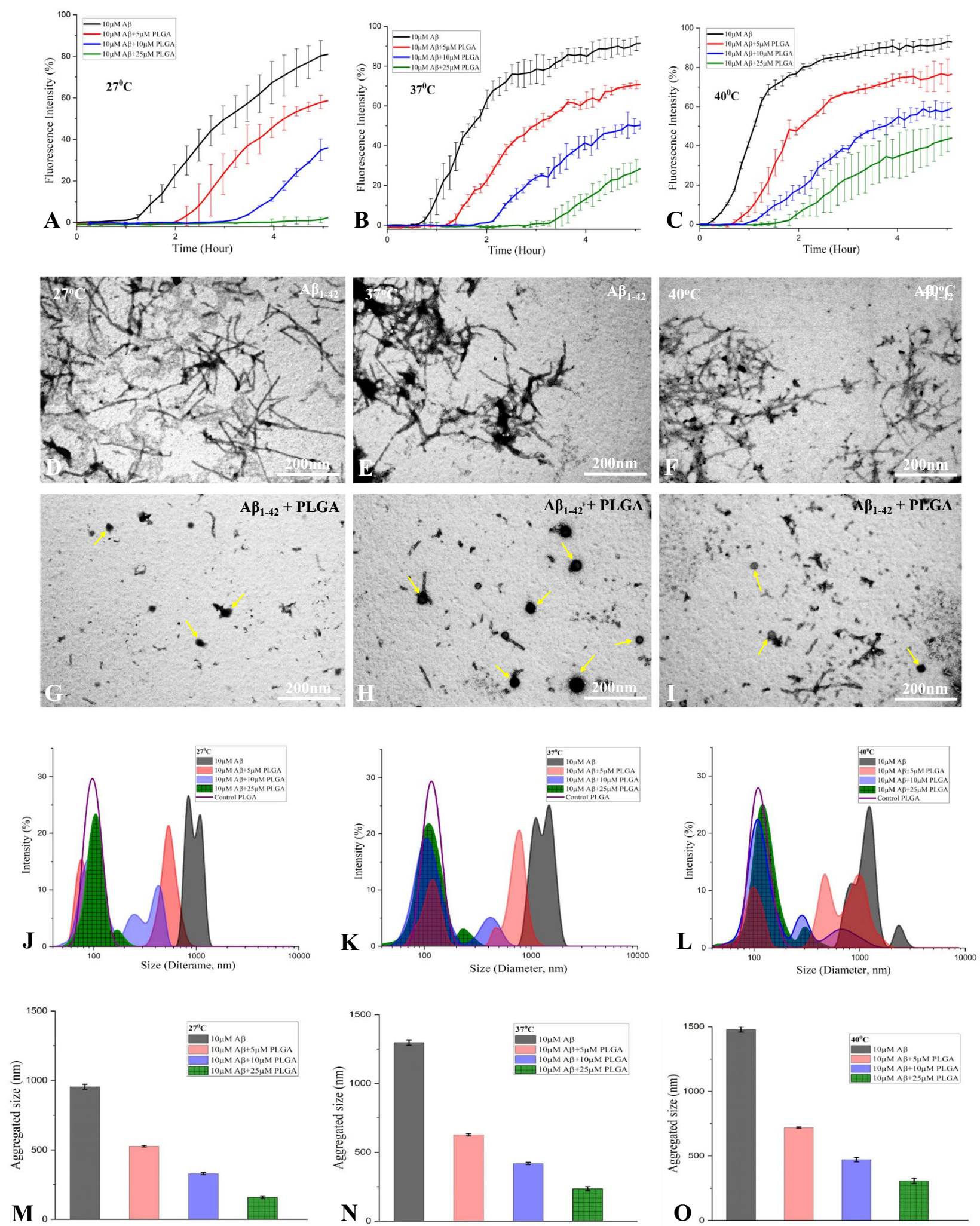

Fig. 6 (See legend on previous page.) 


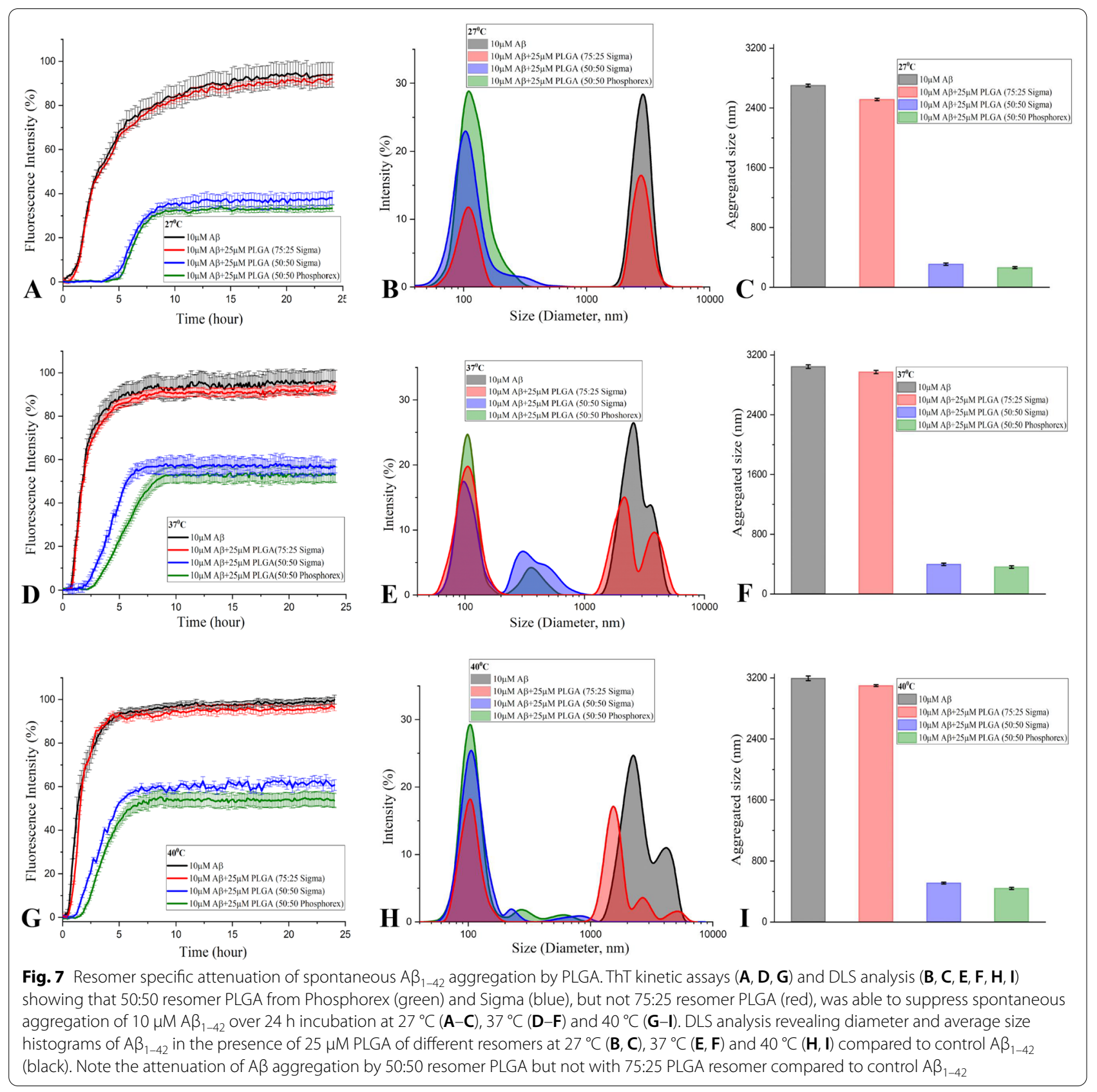

(See figure on next page.)

Fig. 8 Attenuation of spontaneous $A \beta_{1-42}$ aggregation by PLGA vs PCL and PEG-PLGA. ThT kinetic assays $(\mathbf{A}, \mathbf{D}, \mathbf{G})$ and $D L S$ analysis $(\mathbf{B}, \mathbf{C}, \mathbf{E}, \mathbf{F}, \mathbf{H}, \mathbf{I})$ showing effects of PLGA ( $25 \mu \mathrm{M}$; green) compared to PEG-PLGA (5 $\mu \mathrm{M}$; blue) and PCL ( $100 \mathrm{nM}$; red) on spontaneous aggregation of $10 \mu \mathrm{M}$ A $\beta_{1-42}$ (black) over $24 \mathrm{~h}$ incubation at $27^{\circ} \mathrm{C}(\mathbf{A}-\mathbf{C}), 37^{\circ} \mathrm{C}(\mathbf{D}-\mathbf{F})$ and $40^{\circ} \mathrm{C}(\mathbf{G}-\mathbf{I})$. DLS analysis revealing diameter and average size histograms of $A \beta_{1-42}$ in the presence of PLGA (green), PEG-PLGA (blue) and PCL (red) at $27^{\circ} \mathrm{C}(\mathbf{B}, \mathbf{C}), 37^{\circ} \mathrm{C}(\mathbf{E}, \mathbf{F})$ and $40^{\circ} \mathrm{C}(\mathbf{H}, \mathbf{I})$ compared to control A $\beta_{1-42}$ (black). Note that PLGA is more potent in suppressing spontaneous $A \beta_{1-42}$ aggregation than PEG-PLGA and PCL at the studied concentrations. Filter-trap assay and respective quantification data revealing specificty of oligomeric and fibrillar $A \beta_{1-42}$ conformers and their interactions in the presence or absence of 25 MM PLGA nanoparticles as detected using oligomeric specific A11 antobody (J) and fibrillar specific OC antibody (K). Note that presence of PLGA attenauted the detection of both $A \beta_{1-42}$ conformers but the interaction is somewhat more evident with $A \beta$ aggregates than with $A \beta$ oligomers 

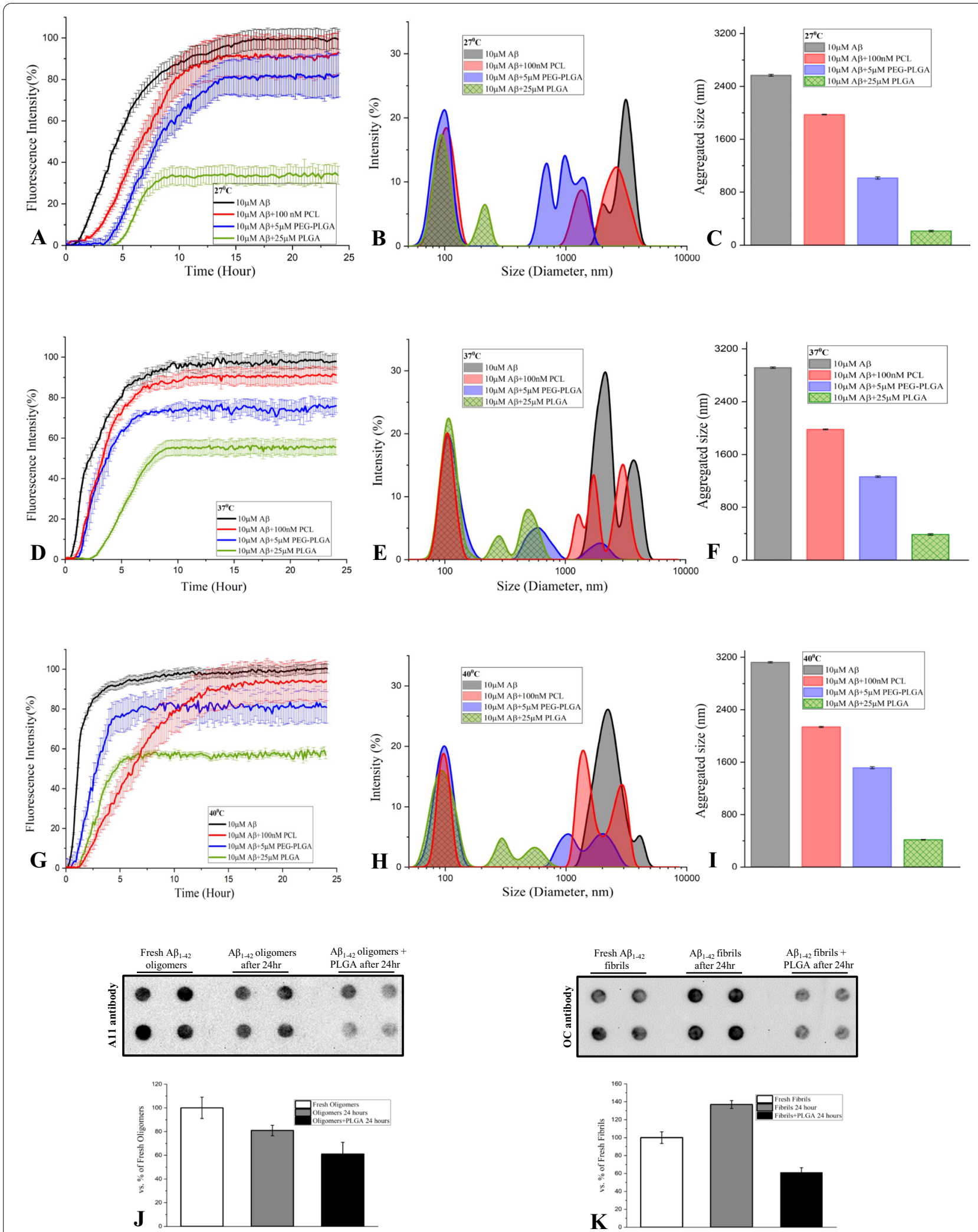

Fig. 8 (See legend on previous page.) 
attenuation of GSK-3 $\beta$, ERK1/2 activation and decreased levels of phosphorylated tau at specific sites (Fig. 10I-K). These results, taken together, indicate that suppression of spontaneous $A \beta$ aggregation or disassembly of aggregated $A \beta$ fibers by PLGA can protect neurons against $\mathrm{A} \beta_{1-42}$-induced toxicity.

\section{PLGA-mediated clearance of labelled $A \beta$ in adult mouse brain}

To establish if native PLGA can influence the breakdown/ clearance of $A \beta_{1-42}$ in the brain, we injected fluorescence labelled $A \beta_{1-42}$ with or without PLGA into the cortical region of mouse brains (Additional file 1: Fig. S4C-E) and then measured intensity of $A \beta$ fluorescence at 6 and $24 \mathrm{~h}$ post-injection period. Fluorescence labelled $A \beta_{1-42}$ was apparent both at 6 and $24 \mathrm{~h}$ after injection in the cortical regions away from the site of injection. Quantification of $\mathrm{A} \beta$ fluorescence intensity relative to DAPI showed a significant decline at $24 \mathrm{~h}$, but not at $6 \mathrm{~h}$, in the cortex of $A \beta+$ PLGA treated mouse brains compared to mice treated with $A \beta$ alone (Fig. 11A-I) suggesting a potential role for PLGA in the breakdown followed by clearance of $A \beta$ peptides. However, these data need to be validated through further study.

\section{Discussion}

The present study using a variety of experimental approaches revealed that FDA-approved biodegradable PLGA nanoparticles can attenuate temperature-dependent $A \beta_{1-42}$ aggregation and protect neurons against $\mathrm{A} \beta$-induced toxicity. This is supported by data which show that: (i) the rate of spontaneous $A \beta_{1-42}$ aggregation increases with a rise in temperature from 27 to $40{ }^{\circ} \mathrm{C}$, (ii) native PLGA of 50:50 resomer compared to other polymorphic nanoparticles such as PEG-PLGA and PCL potently inhibits $A \beta$ aggregation at all studied temperatures partly by influencing a conformational shift from $\alpha$-helix to $\beta$-sheet structure, (iii) PLGA triggers disassembly of matured $A \beta_{1-42}$ fibers at a somewhat faster rate at $40{ }^{\circ} \mathrm{C}$ than $27^{\circ} \mathrm{C}$, (iv) PLGA-treated $\mathrm{A} \beta$ samples increase neuronal viability against $A \beta$ toxicity by regulating tau phosphorylation and (v) native PLGA influences the breakdown/clearance of $A \beta$ peptide in the brain. These results, taken together, suggest that native PLGA can inhibit $A \beta$ aggregation and trigger disassembly of aggregated $A \beta$ at temperatures outside the physiological range and can protect neurons against $A \beta$ toxicity thus suggesting its unique therapeutic potential in the treatment of $\mathrm{AD}$ pathology.

It is accepted that monomeric $A \beta$ exists as an unstructured random-coil, whereas fibrillar forms displays a characteristic cross $-\beta$ structure with stacking of $\beta$ strands perpendicular to the long fiber axis [60-62]. The intramolecular hydrophobic interaction involving amino acid sequence 17-24 (i.e., KLVFFAED) plays a critical role in the formation/stabilization of cross $\beta$-sheet structure. Conversion of monomeric random coil structured $A \beta$ to $\beta$-sheet rich fibers occurs in three distinct phases: the lag phase for nucleation, the growth/linear phase for elongation and the plateau phase associated with aggregation/precipitation of fibrils. The formation of an ordered nucleus is the rate-limiting step in the fibrillization process during which $A \beta$ aggregates are usually absent. Our results showed that the rate of $A \beta_{1-42}$ fibril formation increased with peptide concentrations and rise in temperature from 27 to $40{ }^{\circ} \mathrm{C}$ as monitored by ThT kinetic assay and fluorescence imaging. The duration of the lag phase is reduced as a function of peptide concentration and temperature, whereas the fibril elongation phase is decreased with the rise of temperature at a given peptide concentration, possibly due to enhanced molecular collision facilitating hydrophobic interactions involved in the formation of $A \beta$ fibrils. The subsequent plateau phase, on the other hand, escalated with peptide concentration but not much with the rise in temperature-suggesting that earlier phases of kinetic reactions are more thermodynamically dependent than the plateau phase of $\mathrm{A} \beta$ fibrillogenesis. It is likely that temperature facilitates fibril formation but not the fibrillar content as observed by the ThT binding assays. This is consistent with the reported effects of temperature on $A \beta$ aggregation and fibril growth demonstrating the importance of hydrophobic interactions underlying the $\beta$-sheet formation and aggregation of $A \beta$ peptide $[13,16]$.

Although temperature has been shown to influence the kinetics of amyloid fibril formation [15, 16, 18], very

\footnotetext{
(See figure on next page.)

Fig. 9 PLGA disassembles preaggregated $A \beta_{1-42}$ fibers. ThT kinetic assays showing the disassembly of mature $A \beta_{1-42}$ fibers and the corresponding fluorescence images in the absence and presence of $25 \mu \mathrm{M}$ PLGA over $72 \mathrm{~h}$ incubation at $27^{\circ} \mathrm{C}(\mathbf{A}, \mathbf{D}, \mathbf{E}), 37^{\circ} \mathrm{C}(\mathbf{B}, \mathbf{F}, \mathbf{G})$ and $40^{\circ} \mathrm{C}(\mathbf{C}, \mathbf{H}, \mathbf{I})$. Note the faster rate of $A \beta$ disaggegation with the rise of temperature. Histograms showing the quantification of fluorescence intensity measured in the absence and presence of $25 \mu \mathrm{M}$ PLGA over $72 \mathrm{~h}$ incubation at $27^{\circ} \mathrm{C}(\mathbf{J}), 37^{\circ} \mathrm{C}(\mathbf{K})$ and $40^{\circ} \mathrm{C}(\mathbf{L})$ at saturation which did not differ markedly. STEM images showing matured $A \beta_{1-42}$ fibers in the absence $(\mathbf{M}-\mathbf{O})$ and presence of $25 \mu \mathrm{M} \mathrm{PLGA}(\mathbf{P}-\mathbf{R})$ after $72 \mathrm{~h}$ incubation at $27^{\circ} \mathrm{C}(\mathbf{M}, \mathbf{P}), 37^{\circ} \mathrm{C}$ $(\mathbf{N}, \mathbf{Q})$ and $40^{\circ} \mathrm{C}(\mathbf{O}, \mathbf{R})$. Note the presence of PLGA nanoparticles (arrows) in conjugation with disassembled A $\beta$ fibers at different temperatures. DLS analysis representing diameter of different aggregated $A \beta_{1-42}$ populations in the absence and presence of $25 \mu \mathrm{M}$ PLGA after $72 \mathrm{~h}$ incubation at $27^{\circ} \mathrm{C}(\mathbf{S}), 37^{\circ} \mathrm{C}(\mathbf{T})$ and $40^{\circ} \mathrm{C}(\mathbf{U})$. Note the decreased diameter of aggregated $A \beta_{1-42}$ populations in the presence of $25 \mu \mathrm{M}$ PLGA at different temperatures
} 

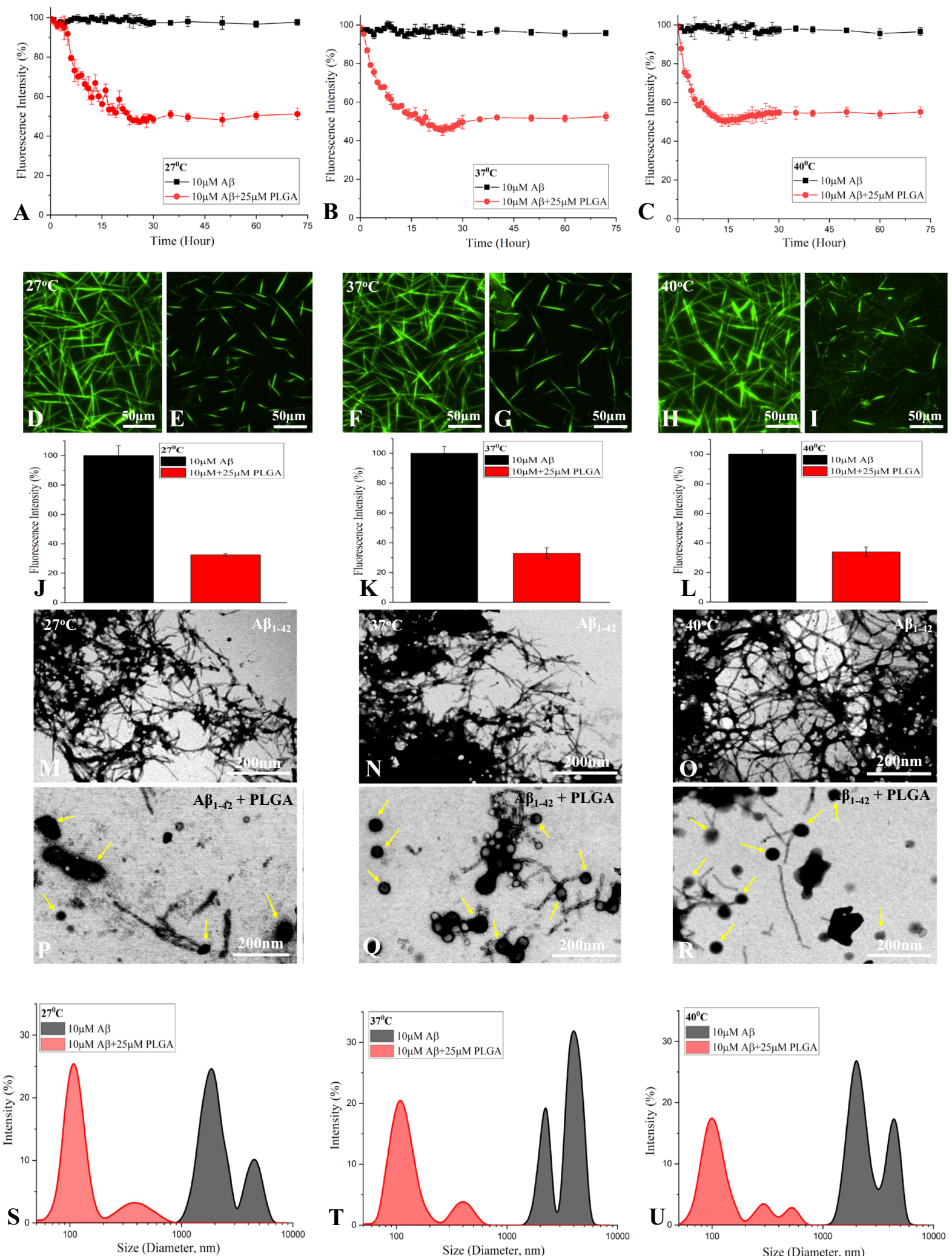

Fig. 9 (See legend on previous page.)

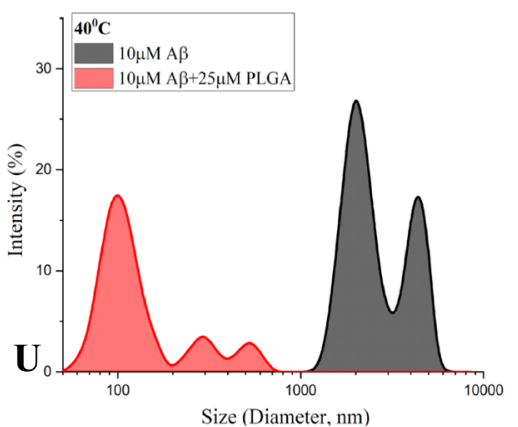


little is known how the presence of a nanoparticle or $\beta$-sheet blocker can impact temperature-dependent amyloid fibrillation. Certain gold nanoparticles have shown to increase $A \beta$ aggregation at high temperature [63], whereas silica (hydrophilic) and polystyrene (hydrophobic) nanoparticles are found to differentially influence peptide aggregation depending on the temperature [18]. This is important for in vivo application of nanoparticles to treat AD-related amyloid pathology as the local temperatures in the brain can vary noticeably $[18,27,64]$. PLGA encapsulated drugs/agents have previously shown to inhibit $A \beta$ aggregation and toxicity, but the effects have been attributed mostly to the interaction of the drugs with $A \beta$ peptide rather than to PLGA [33, 40, 65-70]. Recently, we reported that PLGA without conjugation with any drug/agent can suppress $A \beta$ fibrillization at normal physiological temperature (i.e., $37^{\circ} \mathrm{C}$ ), leading to the generation of shorter/fragmented fibrils [43]. The present result using ThT kinetic assays reveals that unconjugated PLGA of 50:50 resomer, but not 75:25 resomer, can supress temperature dependent spontaneous $\mathrm{A} \beta$ fibrilization outside of the physiological range. This is confirmed by fluorescence imaging, STEM and AFM showing the generation of shorter and fragmented fibrils/spherical globular aggregates as well as DLS analyses in which large fibrils that dominate the light scattering are reduced to smaller species. Furthermore, the suppression of $A \beta_{1-42}$ aggregation by native PLGA was found to be strikingly more potent than some other polymorphic nanoparticles such as PEG-PLGA and PCL. The inhibition, which is evident as a function of PLGA concentration, is mediated not only by delaying the lag phase but also reducing the growth and saturation of $A \beta$ fibrils during the respective linear and equilibrium phases-indicating that all three stages of $A \beta$ fibrillogenesis are affected by native PLGA. This could be due to the interaction of PLGA with A $\beta$ monomers precluding monomer-monomer hydrogen bonding and hydrophobic interactions preventing the development of critical nuclei and the elongation of fibrils. This is supported by liquid phase binding interaction as measured by ITC which showed an enthalpy driven $(\Delta H<0)$ binding between native PLGA and monomeric $A \beta_{1-42}$. It is also possible that PLGA could destabilize the initial assembly to form a $\beta$-sheet rich scaffold during nucleation leading to an equilibrium shift towards the monomeric phase, which may render the elongation process energetically unfavorable. The interaction of PLGA with monomers and/or the scaffold may prolong the lag phase kinetics. Additionally, PLGA can interact with on-pathway species in the elongation phase and slow down the kinetics as evident in our results. This could be due to chirality of PLGA, which triggers binding with $A \beta$ oligomers in the elongation phase through $\pi-\pi$ and hydrophobic interactions resulting in destabilization of on-pathway and formation of off-pathway intermediates containing a mixture of $\alpha$-helical and $\beta$-sheet conformations. This is supported partly by our filter-trap analysis showing an attenuation of $\mathrm{A} \beta_{1-42}$ oligomer content following exposure to unconjugated PLGA as well as our CD data which showed that PLGA nanoparticles enable $A \beta$ peptides to remain more in a non-fibrillar state as apparent by reduced $\beta$-sheet structures.

It is of interest to note that $A \beta$ fibril formation though increased with temperature as reported in earlier studies $[12,13,16]$, suppression of spontaneous $A \beta$ aggregation by PLGA is found to be inversely proportional to the temperature, specifically at higher concentrations of the nanoparticles. This is apparent not only in the ThT kinetic assays but also in fluorescence imaging, STEM, AFM and DLS analyses. Considering an increase in $\beta$-sheet structure in CD spectroscopy with rise in temperature, it appears that native PLGA is more effective at $27{ }^{\circ} \mathrm{C}$ than $40{ }^{\circ} \mathrm{C}$ in preventing the conversion of monomeric $A \beta$ to fibrillar aggregates. This could be either due to; (i) slower $A \beta$ aggregation kinetics, (ii) increased binding with $A \beta$ monomer and/or nuclei or (iii) attenuating formation of off-pathway oligomeric intermediates. If any of these phenomena is involved in the detection of higher populations of small globular aggregates observed at 27 vs $40^{\circ} \mathrm{C}$ remains to be determined from future study.

Accompanying attenuation of spontaneous $A \beta$ aggregation, we observed that unconjugated PLGA can trigger disassembly of pre-aggregated $A \beta$ fibers at all temperatures over an $72 \mathrm{~h}$ incubation period. This is evident by

\footnotetext{
(See figure on next page.)

Fig. 10 PLGA nanoparticles protect cultured neurons. Histogram depicting dose-dependent decrease in the viability of mouse cortical cultured neurons following $24 \mathrm{~h}$ exposure with oligomeric human $A \beta_{1-42}$ compared to control (CTL) neurons as revealed by MTT (A) and LDH (B) assays. Histograms showing protection of mouse cultured neurons following co-treatment of $10 \mu \mathrm{M} \mathrm{A} \beta_{1-42}$ with $25 \mu \mathrm{M}$ PLGA over $24 \mathrm{~h}$ as detected with MTT (C) and LDH (D) assays. Histograms showing protection of primary cortical neurons following treatment with $A \beta_{1-42}$ samples collected after $25 \mu \mathrm{M}$ PLGA-mediated spontaneous attenuation of $A \beta_{1-42}$ aggregation $(\mathbf{E}, \mathbf{F})$ and disassembled of matured $A \beta_{1-42}$ fibers $(\mathbf{G}, \mathbf{H})$ at $37^{\circ} \mathrm{C}$ as detected with $\operatorname{MTT}(\mathbf{E}, \mathbf{G})$ and LDH $(\mathbf{F}, \mathbf{H})$ assays. Immunoblots and histograms showing that protective effects following attenuation of spontaneous $A \beta$ aggregation by PLGA are associated with a decrease in the levels of Phospho-Tyr ${ }^{216} \mathrm{GSK}-3 \beta$ (I), Phospho-ERK1/2 (J) and Phospho-tau (K) induced by $10 \mu \mathrm{M} \mathrm{A} \beta_{1-42}$ alone. All results, which are presented as means $\pm \mathrm{SEM}$, were obtained from three to five separate experiments. ${ }^{* *} p<0.01,{ }^{* * *} p$ $<0.001$
} 

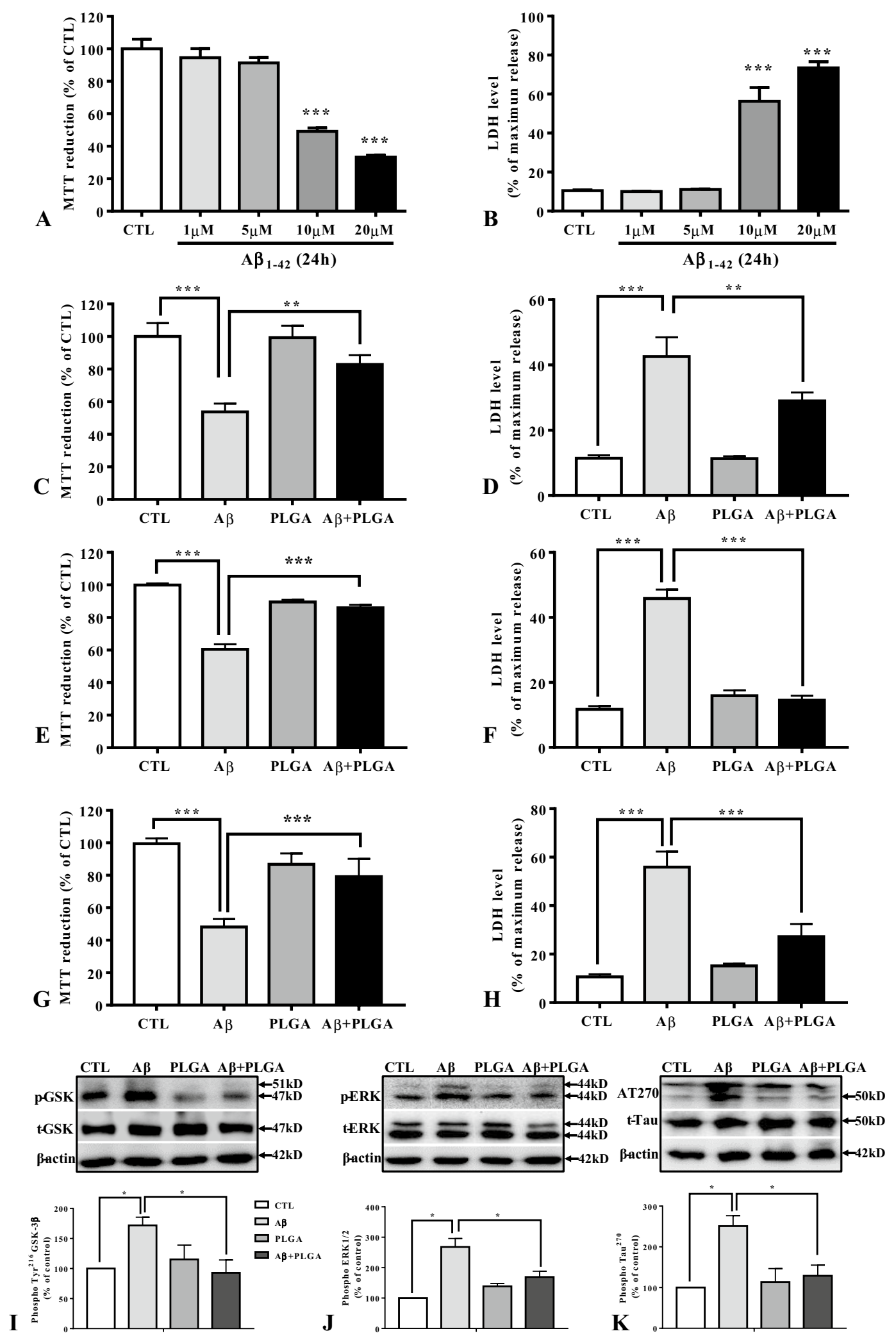

Fig. 10 (See legend on previous page.) 

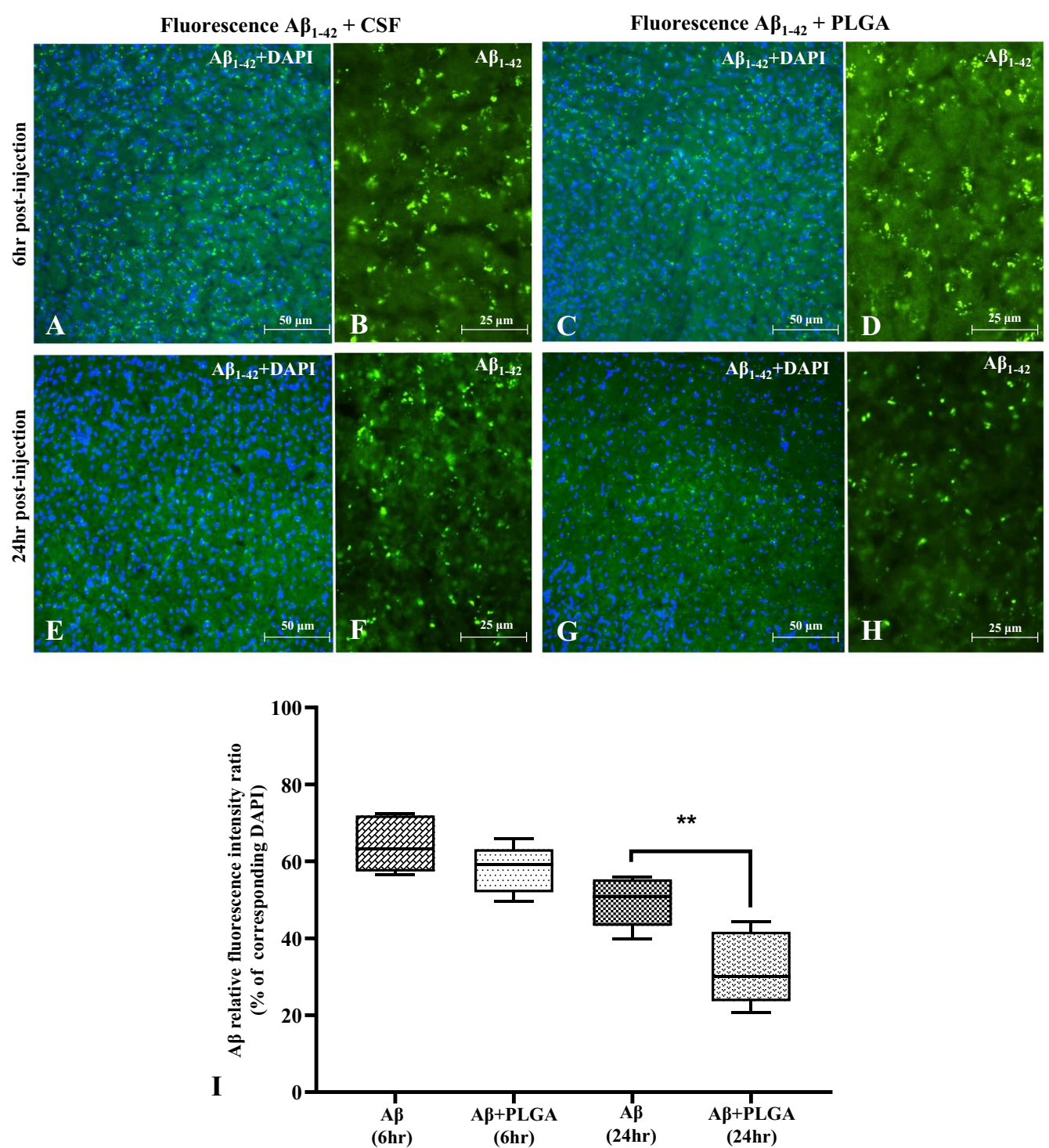

Fig. 11 PLGA facilitates breakdown/clearance of injected $A \beta$ in mouse brain. Photomicrographs depicting injected fluorescein labelled (green) $A \beta_{1-42}$ peptide with $(\mathbf{A}, \mathbf{C}, \mathbf{E}, \mathbf{G})$ or without $(\mathbf{B}, \mathbf{D}, \mathbf{F}, \mathbf{H})$ DAPI at $6 \mathrm{~h}(\mathbf{A}-\mathbf{D})$ and $24 \mathrm{~h}(\mathbf{E}-\mathbf{H})$ in the cortex of CSF- $(\mathbf{A}, \mathbf{B}, \mathbf{E}, \mathbf{F})$ and PLGA $(\mathbf{C}, \mathbf{D}$, $\mathbf{G}, \mathbf{H}$ )-injected mice. Note the decreased level of fluorescein labelled $A \beta_{1-42}$ peptide in PLGA-treated brain slices at $24 \mathrm{~h}(\mathbf{F}, \mathbf{H})$, but not at $6 \mathrm{~h}$ $(\mathbf{B}, \mathbf{D})$, compared to CSF-treated brain slices. I Histograms showing the quantification of A $\beta$ relative fluorescence intensity ratio as percentage corresponding to their DAPI intensities at $6 \mathrm{~h}$ and $24 \mathrm{~h}$ in the cortex of CSF- and PLGA-injected mice brain tissue slices. Note the significant decrease of A fluorescence intensity at $24 \mathrm{~h}$, but not at $6 \mathrm{~h}$, in mice injected with PLGA compared to CSF-injected mice. All data expressed as mean \pm SEM were obtained from the quantifications of three to five zones of tissue section from each group. CSF, artificial cerebrospinal fluid. ${ }^{* *} p<0.01$

our ThT kinetic assays, fluorescence imaging, STEM, DLS and filter-trap analyses. Evidence suggests that the hydrophobicity of the $A \beta$ peptide increases once it undergoes aggregation forming oligomers and fibrils [11, 71]. Apart from the hydrophobic $\mathrm{Lys}_{16}$ to $\mathrm{Ala}_{21}$ domain certain other residues such as $\mathrm{His}_{14}, \mathrm{Gln}_{15}, \mathrm{Ala}_{30}, \mathrm{Ile}_{31}, \mathrm{Met}_{35}$ and $\mathrm{Val}_{36}$ are known to play a role in the $\mathrm{A} \beta$ oligomerization and fibril formation. The $\mathrm{C}$ terminal domain is also involved in the formation of the protofilament structures due to generation of a hydrophobic core between the residues $\mathrm{Ile}_{41}$ and $\mathrm{Val}_{39}$ with the adjacent fibril. The $\mathrm{N}$ terminal domain of a fibril close to the $\mathrm{C}$ terminal domain of another fibril may also induce the formation of a salt bridge through intermolecular interactions between $\mathrm{Asp}_{1}$ and $\mathrm{Lys}_{28}$-an interaction that stabilizes the interface between the two protofilaments [72, 73]. Our previous 
molecular docking analysis revealed that PLGA can interfere with the salt bridges and with the residues present in the steric zipper domain-an interaction that can trigger disassembly of the preformed fibrillar structure [43]. Similar phenomena have been reported using a variety of phytochemicals, peptides and polymers including curcumin, clioquinol, epigallocatechin gallate, polyproline and myricetin [74-78]. Our results also revealed that intracerebral injection of unconjugated PLGA can attenuate the levels of administered fluorescently labelled $A \beta$ peptide suggesting PLGA, as observed under in vitro condition, may influence breakdown followed by clearance of $A \beta$ peptide under in vivo condition, though this needs to be validated from further experiments.

Apart from suppressing $A \beta$ aggregation, we showed spontaneous inhibition of $A \beta$ aggregation by PLGA can markedly increase viability of cultured cortical neurons. Disassembly of aggregated A $\beta$ fibers by PLGA also found to attenuate cell toxicity compared to aggregated fibers. The protective effect is accompanied by reducing phosphorylation of tau protein and its associated signaling pathway. This is likely due to the retention of $A \beta$ monomers or sequestration of $A \beta$ peptides into amorphous aggregates, which are less toxic than metastable $A \beta$ oligomers/aggregates $[58,71,79,80]$. Since temperaturedependent changes are reversible [81] we evaluated the protective effect of PLGA treated $A \beta$ samples incubated for $24 \mathrm{~h}$ at $37^{\circ} \mathrm{C}$-the temperature used in culturing/ maintaining primary neurons. However, it would be of interest to determine if maintaining and treating neurons at different temperatures (i.e., 27, 37 and $40{ }^{\circ} \mathrm{C}$ ) with PLGA treated $A \beta$ samples incubated $24 \mathrm{~h}$ with the corresponding temperature can differentially affect neuronal viability. This will highlight the potential of PLGA to protect neurons against $A \beta$ toxicity by inhibiting the formation or triggering the disassembly of higher-order aggregates.

At present, there is no effective treatment to prevent/arrest the progression of $\mathrm{AD}$. The cholinesterase inhibitors and the glutamate NMDA receptor antagonist memantine that have been approved for the treatment provide symptomatic relief for only a fraction of AD patients $[9,82,83]$. The beneficial effects of recently approved disease modifying $A \beta$ monoclonal antibody Aducanumab on AD patients remain to be determined $[84,85]$. Some earlier studies have shown that PLGA nanoparticles functionalized with various drugs/agents such as donepezil, galantamine, quercetin, memantine and curcumin can exhibit beneficial effects on cellular and/or animal models of AD compared to cells/mice treated with drugs alone or vehicles used for dissolving drugs/PLGA nanoparticles [37, 39, 40, 67, 69, 70, 86,
87]. Interestingly, our recent study reveals that unconjugated PLGA nanoparticles by inhibiting $A \beta$ aggregation/toxicity can also attenuate AD-related pathology in cellular and animal models of AD [43]. However, no study has evaluated if PLGA can influence $A \beta$ aggregation kinetics at different temperatures which affect multiple facets of $\mathrm{A} \beta$ pathology $[12,16,24,62,88,89]$ and fluctuate from 33.4 to $42{ }^{\circ} \mathrm{C}$ in brain disease/pathological conditions $[18,27,28]$. Intriguingly, unconjugated PLGA, as apparent from this study, can inhibit spontaneous aggregation and trigger disassembly of aggregated $A \beta$ at various temperatures (i.e., $27-40{ }^{\circ} \mathrm{C}$ ). PLGA treated $A \beta$ samples can also increase viability of cultured cortical neurons by regulating conformational state of $A \beta$ peptide and its associated cellular signaling pathway involving site-specific phosphorylation of tau protein. Additionally, unconjugated PLGA was found to influence the breakdown/clearance of fluorescence labelled $A \beta_{1-42}$ in the brain. Although these results need to be validated from further study, they highlight the significance of unconjugated PLGA in targeting $A \beta$ peptide and its unique therapeutic potential in the treatment of AD.

\section{Abbreviations}

AB: Amyloid $\beta ;$ AD: Alzheimer's disease; AFM: Atomic force microscopy; CD: Circular dichroism; DLS: Dynamic light scattering; DMEM: Dulbecco's modified Eagle's medium; DMSO: Dimethyl sulfoxide; FBS: Fetal bovine serum; HBSS: Hanks' balanced salt solution; HFIP: Hexafluoro-2-propanol; ITC: Isothermal titration calorimetry; LDH: Lactate dehydrogenase; MTT: 3-(4,5-Dimethylthiazolyl)-2,5-diphenyltetrazolium bromide; PBS: Phosphatebuffered saline; PCL: Polycaprolactone; PLGA: Poly(D,L-lactide-co-glycolide); PEG-PLGA: Polyethylene glycol-PLGA; STEM: Scanning transmission electron microscopy; ThT: Thioflavin-T.

\section{Supplementary Information}

The online version contains supplementary material available at https://doi. org/10.1186/s12951-022-01269-0.

Additional file 1: Figure S1. ThT kinetic assays showing aggregation of 2.5-20 $\mu \mathrm{M} \mathrm{A} \beta_{1-42}$ over a $24 \mathrm{~h}$ incubation at $27^{\circ} \mathrm{C}(\mathbf{A}), 37^{\circ} \mathrm{C}(\mathbf{B})$ and $40^{\circ} \mathrm{C}$ (C). Figure S2. A-CThT assays showing aggregation kinetics $(\mathbf{A}, \mathbf{D}, \mathbf{G})$ and respective fluorescence images of $10 \mu \mathrm{MA} \beta_{1-42}(\mathbf{B}, \mathbf{E}, \mathbf{H})$ and $10 \mu \mathrm{MA} \beta_{42-1}$ $(\mathbf{C}, \mathbf{F}, \mathbf{I})$ over $24 \mathrm{~h}$ incubation at $27^{\circ} \mathrm{C}(\mathbf{A}-\mathbf{C}), 37^{\circ} \mathrm{C}(\mathbf{D}-\mathbf{F})$ and $40^{\circ} \mathrm{C}(\mathbf{G}-\mathbf{I})$. Note the absence of $A \beta_{42-1}$ aggregation at any temperature over $24 \mathrm{~h}$ incubation. Figure S3. DLS analysis depicting a peak of $\sim 100 \mathrm{~nm}$ diameter for unconjugated PLGA and its stability in phosphate buffer over $48 \mathrm{~h}$ at $27^{\circ} \mathrm{C}(\mathbf{A}, \mathbf{B}), 37^{\circ} \mathrm{C}(\mathbf{C}, \mathbf{D})$ and $40^{\circ} \mathrm{C}(\mathbf{E}, \mathbf{F})$. DLS analysis depicting a peak of $\sim 100 \mathrm{~nm}$ diameter for PLGA in phosphate buffer $(\mathbf{G})$ and its stability at $37^{\circ} \mathrm{C}$ over $48 \mathrm{~h}$ in culture medium $(\mathbf{H}, \mathbf{I})$. Note that PLGA nanoparticles are quite stable both in the phosphohate buffer as well as in culture medium over $48 \mathrm{~h}$ period. Figure $\mathbf{S 4}$. Histograms showing protection of mouse cultured neurons following co-treatment of $10 \mu \mathrm{M} \mathrm{A} \beta_{1-42}$ with $5 \mu \mathrm{M}$ PEG-PLGA (A) or 100 nM PCL (B) over $24 \mathrm{~h}$ compared to neurons treated with $10 \mu \mathrm{MA} \beta_{1-42}$ as detected using MTT assay. C-E Mouse brain section showing the site of fluoresence $A \beta_{1-42}$ injection (arrow) using Hamilton syringe under anesthesia. The brain section shows nuclear labelling with $\operatorname{DAPI}(\mathbf{C})$, presence of fluoresence $A \beta_{1-42}(\mathbf{D})$ and the merged image $(\mathbf{E})$. 


\section{Authors' contributions}

PSP, JYC, QW, GK and EG did the experiments and analyzed the data included in the manuscript. SK, helped in analyzing the data and wrote the manuscript with help/input from PSP, JYC, QW, GK, EG, HW and MK. All authors read and approved the final manuscript.

\section{Funding}

This work was supported by grants from APRI-ASANT and CIHR (MOP-84480) to SK and from APRI (APRI 201600028) to HW. SynAD, University of Alberta provided a part of the postdoctoral fellowships for PSP and QW.

\section{Availability of data and materials}

The data in this work are available in the manuscript or Additional file or available from the corresponding author upon reasonable request.

\section{Declarations}

Ethics approval and consent to participate

All research involving the animals has been approved and maintained according to the University of Alberta Animal Care and Use Committee and the Canadian Council on Animal Care guidelines.

\section{Consent for publication}

All authors consent to the publication of this study.

\section{Competing interests}

The authors declare no competing interests or personal relationships that could have appeared to influence the work reported in this paper.

\section{Author details}

${ }^{1}$ Department of Medicine (Neurology), Centre for Prions and Protein Folding Diseases, University of Alberta, Edmonton, AB T6G 2M8, Canada. ${ }^{2}$ Nanotechnology Research Centre, National Research Council Canada, Edmonton, AB T6G 2M9, Canada. ${ }^{3}$ Department of Biochemistry, Centre for Prions and Protein Folding Diseases, University of Alberta, Edmonton, AB T6G 2M8, Canada. ${ }^{4}$ Department of Medical Microbiology and Immunology, University of Alberta, Edmonton, AB T6G 2E1, Canada. ${ }^{5}$ Departments of Medicine (Neurology) and Psychiatry, Centre for Prions and Protein Folding Diseases, University of Alberta, Edmonton, AB T6G 2M8, Canada.

Received: 11 July 2021 Accepted: 16 January 2022

Published online: 04 February 2022

\section{References}

1. Chen XQ, Mobley WC. Alzheimer disease pathogenesis: insights from molecular and cellular biology studies of oligomeric Abeta and Tau species. Front Neurosci. 2019;13:659.

2. Dawkins $\mathrm{E}$, Small DH. Insights into the physiological function of the betaamyloid precursor protein: beyond Alzheimer's disease. J Neurochem. 2014;129:756-69.

3. Lane CA, Hardy J, Schott JM. Alzheimer's disease. Eur J Neurol. 2018;25:59-70.

4. Straub JE, Thirumalai D. Toward a molecular theory of early and late events in monomer to amyloid fibril formation. Annu Rev Phys Chem. 2011;62:437-63.

5. Selkoe DJ, Hardy J. The amyloid hypothesis of Alzheimer's disease at 25 years. EMBO Mol Med. 2016;8:595-608.

6. Bisceglia F, Natalello A, Serafini MM, Colombo R, Verga L, Lanni C, De Lorenzi $E$. An integrated strategy to correlate aggregation state, structure and toxicity of Ass 1-42 oligomers. Talanta. 2018;188:17-26.

7. Maulik M, Westaway D, Jhamandas JH, Kar S. Role of cholesterol in APP metabolism and its significance in Alzheimer's disease pathogenesis. Mol Neurobiol. 2013;47:37-63.

8. Ittner A, Chua SW, Bertz J, Volkerling A, van der Hoven J, Gladbach A Przybyla M, Bi M, van Hummel A, Stevens CH, et al. Site-specific phosphorylation of tau inhibits amyloid-beta toxicity in Alzheimer's mice. Science. 2016;354:904-8.
9. Revett TJ, Baker GB, Jhamandas J, Kar S. Glutamate system, amyloid ss peptides and tau protein: functional interrelationships and relevance to Alzheimer disease pathology. J Psychiatry Neurosci. 2013;38:6-23.

10. Chen GF, Xu TH, Yan Y, Zhou YR, Jiang Y, Melcher K, Xu HE. Amyloid beta: structure, biology and structure-based therapeutic development. Acta Pharmacol Sin. 2017;38:1205-35.

11. Lee SJ, Nam E, Lee HJ, Savelieff MG, Lim MH. Towards an understanding of amyloid-beta oligomers: characterization, toxicity mechanisms, and inhibitors. Chem Soc Rev. 2017:46:310-23.

12. Kusumoto Y, Lomakin A, Teplow DB, Benedek GB. Temperature dependence of amyloid beta-protein fibrillization. Proc Natl Acad Sci USA. 1998;95:12277-82.

13. Gursky O, Aleshkov S. Temperature-dependent beta-sheet formation in beta-amyloid Abeta(1-40) peptide in water: uncoupling beta-structure folding from aggregation. Biochim Biophys Acta. 2000;1476:93-102.

14. Yanagisawa K, Matsuzaki K. Cholesterol-dependent aggregation of amyloid beta-protein. Ann NY Acad Sci. 2002;977:384-6.

15. Sabate R, Gallardo M, Estelrich J. Temperature dependence of the nucleation constant rate in beta amyloid fibrillogenesis. Int J Biol Macromol. 2005:35:9-13.

16. Lin MS, Chen LY, Tsai HT, Wang SS, Chang Y, Higuchi A, Chen WY. Investigation of the mechanism of beta-amyloid fibril formation by kinetic and thermodynamic analyses. Langmuir. 2008;24:5802-8.

17. Hsu F, Park G, Guo Z. Key residues for the formation of Abeta42 amyloid fibrils. ACS Omega. 2018;3:8401-7.

18. Ghavami M, Rezaei M, Ejtehadi R, Lotfi M, Shokrgozar MA, Abd Emamy B, Raush J, Mahmoudi M. Physiological temperature has a crucial role in amyloid beta in the absence and presence of hydrophobic and hydrophilic nanoparticles. ACS Chem Neurosci. 2013;4:375-8.

19. Naiki H, Gejyo F. Kinetic analysis of amyloid fibril formation. Methods Enzymol. 1999:309:305-18.

20. Korneyev A, Binder L, Bernardis J. Rapid reversible phosphorylation of rat brain tau proteins in response to cold water stress. Neurosci Lett. 1995;191:19-22.

21. Planel E, Miyasaka T, Launey T, Chui DH, Tanemura K, Sato S, Murayama O, Ishiguro K, Tatebayashi Y, Takashima A. Alterations in glucose metabolism induce hypothermia leading to tau hyperphosphorylation through differential inhibition of kinase and phosphatase activities: implications for Alzheimer's disease. J Neurosci. 2004;24:2401-11.

22. Ahmadian-Attari MM, Dargahi L, Mosaddegh M, Kamalinejad M, Khallaghi B, Noorbala F, Ahmadiani A. Impairment of rat spatial learning and memory in a new model of cold water-induced chronic hypothermia: implication for Alzheimer's disease. Neurotox Res. 2015;28:95-107.

23. El Khoury NB, Gratuze M, Petry F, Papon MA, Julien C, Marcouiller F, Morin F, Nicholls SB, Calon F, Hebert SS, et al. Hypothermia mediates agedependent increase of tau phosphorylation in $\mathrm{db} / \mathrm{db}$ mice. Neurobiol Dis. 2016;88:55-65.

24. Vandal M, White PJ, Tournissac M, Tremblay C, St-Amour I, Drouin-Ouellet J, Bousquet M, Traversy MT, Planel E, Marette A, Calon F. Impaired thermoregulation and beneficial effects of thermoneutrality in the $3 \times \mathrm{Tg}-\mathrm{AD}$ model of Alzheimer's disease. Neurobiol Aging. 2016:43:47-57.

25. Corbett R, Laptook A, Weatherall P. Noninvasive measurements of human brain temperature using volume-localized proton magnetic resonance spectroscopy. J Cereb Blood Flow Metab. 1997;17:363-9.

26. Collins CM, Smith MB, Turner R. Model of local temperature changes in brain upon functional activation. J Appl Physiol. 1985;2004(97):2051-5.

27. Sukstanskii AL, Yablonskiy DA. Theoretical model of temperature regulation in the brain during changes in functional activity. Proc Natl Acad Sci USA. 2006;103:12144-9.

28. Sinigaglia-Coimbra R, Cavalheiro EA, Coimbra CG. Postischemic hyperthermia induces Alzheimer-like pathology in the rat brain. Acta Neuropathol. 2002;103:444-52.

29. Ishigaki D, Ogasawara K, Yoshioka Y, Chida K, Sasaki M, Fujiwara S, Aso K, Kobayashi M, Yoshida K, Terasaki K, et al. Brain temperature measured using proton MR spectroscopy detects cerebral hemodynamic impairment in patients with unilateral chronic major cerebral artery steno-occlusive disease: comparison with positron emission tomography Stroke. 2009:40:3012-6.

30. Laukkanen T, Kunutsor S, Kauhanen J, Laukkanen JA. Sauna bathing is inversely associated with dementia and Alzheimer's disease in middleaged Finnish men. Age Ageing. 2017;46:245-9. 
31. Ashraf GM, Tabrez S, Jabir NR, Firoz CK, Ahmad S, Hassan I, Alexiou A, Kamal MA. An overview on global trends in nanotechnological approaches for Alzheimer therapy. Curr Drug Metab. 2015;16:719-27.

32. Ansari SA, Satar R, Perveen A, Ashraf GM. Current opinion in Alzheimer's disease therapy by nanotechnology-based approaches. Curr Opin Psychiatry. 2017;30:128-35.

33. Hajipour MJ, Santoso MR, Rezaee F, Aghaverdi H, Mahmoudi M, Perry G. Advances in Alzheimer's diagnosis and therapy: the implications of nanotechnology. Trends Biotechnol. 2017;35:937-53.

34. Saraf J, Kalia K, Bhattacharya P, Tekade RK. Growing synergy of nanodiamonds in neurodegenerative interventions. Drug Discov Today. 2019;24:584-94.

35. Tosi G, Pederzoli F, Belletti D, Vandelli MA, Forni F, Duskey JT, Ruozi B. Nanomedicine in Alzheimer's disease: amyloid beta targeting strategy. Prog Brain Res. 2019;245:57-88.

36. Danhier F, Ansorena E, Silva JM, Coco R, Le Breton A, Preat V. PLGA-based nanoparticles: an overview of biomedical applications. J Control Release. 2012;161:505-22.

37. Baysal I, Ucar G, Gultekinoglu M, Ulubayram K, Yabanoglu-Ciftci S. Donepezil loaded PLGA-b-PEG nanoparticles: their ability to induce destabilization of amyloid fibrils and to cross blood brain barrier in vitro. J Neural Transm. 2017;124:33-45.

38. Ding D, Zhu Q. Recent advances of PLGA micro/nanoparticles for the delivery of biomacromolecular therapeutics. Mater Sci Eng C Mater Biol Appl. 2018;92:1041-60.

39. Fan S, Zheng Y, Liu X, Fang W, Chen X, Liao W, Jing X, Lei M, Tao E, $M a$ Q, et al. Curcumin-loaded PLGA-PEG nanoparticles conjugated with $\mathrm{B} 6$ peptide for potential use in Alzheimer's disease. Drug Deliv. 2018:25:1091-102.

40. Sanchez-Lopez E, Ettcheto M, Egea MA, Espina M, Cano A, Calpena AC, Camins A, Carmona N, Silva AM, Souto EB, Garcia ML. Memantine loaded PLGA PEGylated nanoparticles for Alzheimer's disease: in vitro and in vivo characterization. J Nanobiotechnol. 2018;16:32.

41. Wang Y, Qin B, Xia G, Choi SH. FDA's poly (lactic-co-glycolic acid) research program and regulatoryoutcomes. AAPS J. 2021;23:92. https://doi.org/10. 1208/s12248-021-00611-y.

42. Wang Y, Wu Q, Anand BG, Karthivashan G, Phukan G, Yang J, Thinakaran G, Westaway D, Kar S. Significance of cytosolic cathepsin D in Alzheimer's disease pathology: protective cellular effects of PLGA nanoparticles against beta-amyloid-toxicity. Neuropathol Appl Neurobiol. 2020;46:686-706.

43. Anand BG WQ, Nejad MN, Karthivashan G, Dorosh L, Amidian S, Dahal A, Stepanova M, Wille H, Giuliani F, Kar S. Significance of unconjugated PLGA nanoparticles in the treatment of Alzheimer's disease pathology. (Unpublished data)

44. Foroutanpay BV, Kumar J, Kang SG, Danaei N, Westaway D, Sim VL, Kar S. The effects of $\mathrm{N}$-terminal mutations on beta-amyloid peptide aggregation and toxicity. Neuroscience. 2018;379:177-88.

45. Anand BG, Wu Q, Karthivashan G, Shejale KP, Amidian S, Wille H, Kar S. Mimosine functionalized gold nanoparticles (Mimo-AuNPs) suppress beta-amyloid aggregation and neuronal toxicity. Bioact Mater. 2021;6:4491-505.

46. Wang Q, Shah N, Zhao J, Wang C, Zhao C, Liu L, Li L, Zhou F, Zheng J. Structural, morphological, and kinetic studies of beta-amyloid peptide aggregation on self-assembled monolayers. Phys Chem Chem Phys. 2011;13:15200-10.

47. Li X, Zhang X, Ladiwala AR, Du D, Yadav JK, Tessier PM, Wright PE, Kelly JW, Buxbaum JN. Mechanisms of transthyretin inhibition of beta-amyloid aggregation in vitro. J Neurosci. 2013;33:19423-33.

48. Dahlgren KN, Manelli AM, Stine WB Jr, Baker LK, Krafft GA, LaDu MJ. Oligomeric and fibrillar species of amyloid-beta peptides differentially affect neuronal viability. J Biol Chem. 2002;277:32046-53.

49. Song MS, Rauw G, Baker GB, Kar S. Memantine protects rat cortical cultured neurons against beta-amyloid-induced toxicity by attenuating tau phosphorylation. Eur J Neurosci. 2008;28:1989-2002.

50. Maity S, Lyubchenko YL. AFM probing of amyloid-beta 42 dimers and trimers. Front Mol Biosci. 2020;7:69.

51. Wei Z, Song MS, MacTavish D, Jhamandas JH, Kar S. Role of calpain and caspase in beta-amyloid-induced cell death in rat primary septal cultured neurons. Neuropharmacology. 2008;54:721-33.
52. Amritraj A, Wang Y, Revett TJ, Vergote D, Westaway D, Kar S. Role of cathepsin D in U18666A-induced neuronal cell death: potential implication in Niemann-Pick type C disease pathogenesis. J Biol Chem. 2013;288:3136-52.

53. Hawkes C, Kabogo D, Amritraj A, Kar S. Up-regulation of cation-independent mannose 6-phosphate receptor and endosomal-lysosomal markers in surviving neurons after 192-lgG-saporin administrations into the adult rat brain. Am J Pathol. 2006;169:1140-54.

54. Maulik M, Ghoshal B, Kim J, Wang Y, Yang J, Westaway D, Kar S. Mutant human APP exacerbates pathology in a mouse model of NPC and its reversal by a beta-cyclodextrin. Hum Mol Genet. 2012;21:4857-75.

55. Wu Q, Cortez L, Kamali-Jamil R, Sim V, Wille H, Kar S. Implication of exosomes derived from cholesterol-accumulated astrocytes in Alzheimer's disease pathology. Dis Model Mech. 2021. https://doi.org/10.1242/ dmm.048929.

56. Lin H, Yue Y, Maidana DE, Bouzika P, Atik A, Matsumoto H, Miller JW, Vavvas DG. Drug delivery nanoparticles: toxicity comparison in retinal pigment epithelium and retinal vascular endothelial cells. Semin Ophthalmol. 2016;31:1-9.

57. Lukasiewicz S, Mikolajczyk A, Blasiak E, Fic E, Dziedzicka-Wasylewska M. Polycaprolactone nanoparticles as promising candidates for nanocarriers in novel nanomedicines. Pharmaceutics. 2021. https://doi.org/10.3390/ pharmaceutics13020191.

58. Reiss AB, Arain HA, Stecker MM, Siegart NM, Kasselman LJ. Amyloid toxicity in Alzheimer's disease. Rev Neurosci. 2018;29:613-27.

59. Zheng WH, Bastianetto S, Mennicken F, Ma W, Kar S. Amyloid beta peptide induces tau phosphorylation and loss of cholinergic neurons in rat primary septal cultures. Neuroscience. 2002;115:201-11.

60. Teplow DB. Structural and kinetic features of amyloid beta-protein fibrillogenesis. Amyloid. 1998;5:121-42.

61. Galzitskaya OV, Galushko El, Selivanova OM. Studies of the process of amyloid formation by Abeta peptide. Biochemistry. 2018;83:S62-80.

62. Buell AK. The growth of amyloid fibrils: rates and mechanisms. Biochem J. 2019;476:2677-703

63. Kim HY, Choi I. Ultrafast colorimetric determination of predominant protein structure evolution with gold nanoplasmonic particles. Nanoscale. 2016;8:1952-9.

64. Krol S, Macrez R, Docagne F, Defer G, Laurent S, Rahman M, Hajipour MJ, Kehoe PG, Mahmoudi M. Therapeutic benefits from nanoparticles: the potential significance of nanoscience in diseases with compromise to the blood brain barrier. Chem Rev. 2013;113:1877-903.

65. Huo X, Zhang Y, Jin X, Li Y, Zhang L. A novel synthesis of selenium nanoparticles encapsulated PLGA nanospheres with curcumin molecules for the inhibition of amyloid beta aggregation in Alzheimer's disease. J Photochem Photobiol B. 2019;190:98-102.

66. Baysal I, Yabanoglu-Ciftci S, Tunc-Sarisozen Y, Ulubayram K, Ucar G. Interaction of selegiline-loaded PLGA-b-PEG nanoparticles with beta-amyloid fibrils. J Neural Transm. 2013;120:903-10.

67. Sun D, Li N, Zhang W, Zhao Z, Mou Z, Huang D, Liu J, Wang W. Design of PLGA-functionalized quercetin nanoparticles for potential use in Alzheimer's disease. Colloids Surf B Biointerfaces. 2016;148:116-29.

68. Sharma S, Nehru B, Saini A. Inhibition of Alzheimer's amyloid-beta aggregation in-vitro by carbenoxolone: insight into mechanism of action. Neurochem Int. 2017;108:481-93.

69. Aalinkeel R, Kutscher HL, Singh A, Cwiklinski K, Khechen N, Schwartz SA, Prasad PN, Mahajan SD. Neuroprotective effects of a biodegradable poly(lactic-co-glycolic acid)-ginsenoside Rg3 nanoformulation: a potential nanotherapy for Alzheimer's disease? J Drug Target. 2018;26:182-93.

70. Silva-Abreu M, Calpena AC, Andres-Benito P, Aso E, Romero IA, RoigCarles D, Gromnicova R, Espina M, Ferrer I, Garcia ML, Male D. PPARgamma agonist-loaded PLGA-PEG nanocarriers as a potential treatment for Alzheimer's disease: in vitro and in vivo studies. Int J Nanomed. 2018;13:5577-90

71. Lee J, Culyba EK, Powers ET, Kelly JW. Amyloid-beta forms fibrils by nucleated conformational conversion of oligomers. Nat Chem Biol. 2011;7:602-9.

72. Hayden EY, Hoi KK, Lopez J, Inayathullah M, Condron MM, Teplow DB. Identification of key regions and residues controlling Abeta folding and assembly. Sci Rep. 2017;7:12434.

73. Gremer L, Scholzel D, Schenk C, Reinartz E, Labahn J, Ravelli RBG, Tusche M, Lopez-Iglesias C, Hoyer W, Heise H, et al. Fibril 
structure of amyloid-beta(1-42) by cryo-electron microscopy. Science. 2017;358:116-9.

74. Thapa A, Jett SD, Chi EY. Curcumin attenuates amyloid-beta aggregate toxicity and modulates amyloid-beta aggregation pathway. ACS Chem Neurosci. 2016;7:56-68.

75. Andarzi Gargari S, Barzegar A, Tarinejad A. The role of phenolic OH groups of flavonoid compounds with $\mathrm{H}$-bond formation ability to suppress amyloid mature fibrils by destabilizing beta-sheet conformation of monomeric Abeta17-42. PLoS ONE. 2018;13:e0199541.

76. Andrade S, Ramalho MJ, Loureiro JA, Pereira MDC. Natural compounds for Alzheimer's disease therapy: a systematic review of preclinical and clinical studies. Int J Mol Sci. 2019;20:2313.

77. Kanchi PK, Dasmahapatra AK. Polyproline chains destabilize the Alzheimer's amyloid-beta protofibrils: a molecular dynamics simulation study. J Mol Graph Model. 2019;93:107456.

78. Stefanescu R, Stanciu GD, Luca A, Paduraru L, Tamba BI. Secondary metabolites from plants possessing inhibitory properties against betaamyloid aggregation as revealed by Thioflavin-T assay and correlations with investigations on transgenic mouse models of Alzheimer's disease. Biomolecules. 2020;10:870.

79. Ahmed M, Davis J, Aucoin D, Sato T, Ahuja S, Aimoto S, Elliott JI, Van Nostrand WE, Smith SO. Structural conversion of neurotoxic amyloidbeta(1-42) oligomers to fibrils. Nat Struct Mol Biol. 2010;17:561-7.

80. Sonzini S, Stanyon HF, Scherman OA. Decreasing amyloid toxicity through an increased rate of aggregation. Phys Chem Chem Phys. 2017;19:1458-65.

81. Gast K, Modler AJ, Damaschun H, Krober R, Lutsch G, Zirwer D, Golbik R, Damaschun G. Effect of environmental conditions on aggregation and fibril formation of barstar. Eur Biophys J. 2003;32:710-23.

82. Anand R, Gill KD, Mahdi AA. Therapeutics of Alzheimer's disease: past, present and future. Neuropharmacology. 2014;76:27-50.

83. Herrmann N, Chau SA, Kircanski I, Lanctot KL. Current and emerging drug treatment options for Alzheimer's disease: a systematic review. Drugs. 2011;71:2031-65.

84. Avgerinos Kl, Ferrucci L, Kapogiannis D. Effects of monoclonal antibodies against amyloid-beta on clinical and biomarker outcomes and adverse event risks: a systematic review and meta-analysis of phase III RCTs in Alzheimer's disease. Ageing Res Rev. 2021;68:101339.

85. Mukhopadhyay S, Banerjee D. A primer on the evolution of Aducanumab: the first antibody approved for treatment of Alzheimer's disease. J Alzheimers Dis. 2021. https://doi.org/10.3233/JAD-215065.

86. Fornaguera C, Feiner-Gracia N, Caldero G, Garcia-Celma MJ, Solans C. Galantamine-loaded PLGA nanoparticles, from nano-emulsion templating, as novel advanced drug delivery systems to treat neurodegenerative diseases. Nanoscale. 2015;7:12076-84.

87. Jeon SG, Cha MY, Kim Jl, Hwang TW, Kim KA, Kim TH, Song KC, Kim JJ, Moon M. Vitamin D-binding protein-loaded PLGA nanoparticles suppress Alzheimer's disease-related pathology in 5XFAD mice. Nanomedicine. 2019;17:297-307.

88. Eckenhoff RG, Johansson JS, Wei H, Carnini A, Kang B, Wei W, Pidikiti R, Keller JM, Eckenhoff MF. Inhaled anesthetic enhancement of amyloidbeta oligomerization and cytotoxicity. Anesthesiology. 2004;101:703-9.

89. Du Z, Li M, Ren J, Qu X. Current strategies for modulating Abeta aggregation with multifunctional agents. Acc Chem Res. 2021;54:2172-84.

\section{Publisher's Note}

Springer Nature remains neutral with regard to jurisdictional claims in published maps and institutional affiliations.

Ready to submit your research? Choose BMC and benefit from:

- fast, convenient online submission

- thorough peer review by experienced researchers in your field

- rapid publication on acceptance

- support for research data, including large and complex data types

- gold Open Access which fosters wider collaboration and increased citations

- maximum visibility for your research: over $100 \mathrm{M}$ website views per year

At BMC, research is always in progress.

Learn more biomedcentral.com/submissions 